\title{
Characterization of Future Caribbean Rainfall and Temperature Extremes across Rainfall Zones
}

\author{
Natalie Melissa McLean, Tannecia Sydia Stephenson, \\ Michael Alexander Taylor, and Jayaka Danaco Campbell \\ The Climate Studies Group Mona, The University of the West Indies, Mona, Kingston 7, Jamaica \\ Correspondence should be addressed to Tannecia Sydia Stephenson; tannecia.stephenson02@uwimona.edu.jm
}

Received 16 September 2014; Revised 26 January 2015; Accepted 27 January 2015

Academic Editor: Luis Gimeno

Copyright (C) 2015 Natalie Melissa McLean et al. This is an open access article distributed under the Creative Commons Attribution License, which permits unrestricted use, distribution, and reproduction in any medium, provided the original work is properly cited.

End-of-century changes in Caribbean climate extremes are derived from the Providing Regional Climate for Impact Studies (PRECIS) regional climate model (RCM) under the A2 and B2 emission scenarios across five rainfall zones. Trends in rainfall, maximum temperature, and minimum temperature extremes from the RCM are validated against meteorological stations over 1979-1989. The model displays greater skill at representing trends in consecutive wet days (CWD) and extreme rainfall (R95P) than consecutive dry days (CDD), wet days (R10), and maximum 5-day precipitation (RX5). Trends in warm nights, cool days, and warm days were generally well reproduced. Projections for 2071-2099 relative to 1961-1989 are obtained from the ECHAM5 driven RCM. Northern and eastern zones are projected to experience more intense rainfall under A2 and B2. There is less consensus across scenarios with respect to changes in the dry and wet spell lengths. However, there is indication that a drying trend may be manifest over zone 5 (Trinidad and northern Guyana). Changes in the extreme temperature indices generally suggest a warmer Caribbean towards the end of century across both scenarios with the strongest changes over zone 4 (eastern Caribbean).

\section{Introduction}

Model studies of Caribbean climate change have typically assessed changes in the mean state of some key variables. This approach is consistent with the initial pattern of studies done globally $[1,2]$. Future regional projections have been examined for surface temperature, rainfall, wind and wind shear, sea level rise, and sea surface temperature for the middle to end of century [3-13]. The results suggest increases in annual and seasonal land and ocean surface temperatures of 0.6 to $4.0^{\circ} \mathrm{C}$; annual changes in rainfall ranging between -50 and $+13.7 \%$ with a robust summer drying; higher vertical wind shear but lower than $8 \mathrm{~m} / \mathrm{s}$ during May to November; and sea level rise of approximately 18 to $59 \mathrm{~cm}$, with indication of more pronounced levels due to improved model representation of polar dynamics and because of the Caribbean's proximity to the equator. A summary of variables, models, emission scenarios, and projections is presented by $[1,14]$.

Few Caribbean studies have included projections of future weather and climate extremes though global research initiatives have increasingly incorporated extremes over the past two decades given improvements in modelling capabilities and resolution. Reference [15] suggests an increase in the frequency of hot days and night and decreases in frequency of cool days and cool nights and in the proportion of total rainfall that is obtained in heavy events over Caribbean islands by the 2080s under multiple SRES scenarios. They used global climate models (GCMs) regridded to a $2.5^{\circ} \times 2.5^{\circ}$ lat/lon grid. Reference [5] suggest more (less) intense rainfall and less (more) dry days in the northern (southern) Caribbean basin using $0.5^{\circ}$ square grids over seven Caribbean meteorological stations from the Providing Regional Climates for Impact Studies (PRECIS) regional climate model (RCM). Simulations were forced by the HadAM3P GCM under the A2 and B2 scenarios. Reference [14] indicates 5-10\% decrease in the simple daily precipitation intensity with no significant change in the number of consecutive dry days for Cuba, Jamaica, southern Bahamas, and Haiti and an increase in the number of hot days and nights over the main Caribbean basin using the Meteorological Research Institute (MRI) $20 \mathrm{~km}$ mesh 
atmospheric GCM for the A1B scenario for the 2080s. Reference [16] also shows that the annual 5-day maximum rainfall and the maximum number of consecutive dry days are projected to increase over most areas in Central America, Mexico, and Caribbean using three different horizontal resolutions of the MRI model for the A1B scenario for the 2080s. These studies have been extremely useful in contributing to the characterization of extremes for the region but have been limited by either coarseness of model resolution, spatial coverage of analysis, range of extreme indices investigated, or the assumption of homogeneity in the treatment of the Caribbean domain.

Reference [17] commissioned by the Intergovernmental Panel on Climate Change (IPCC) and the accompanying [18] released in 2012 underscore the need for more analyses of observed and projected climate extremes for the Caribbean. The reports suggest there is medium confidence of observed increases in warm days and nights and decreases in cool days and nights over the Caribbean. There is also medium confidence in the projected temperature increases across the Caribbean. The report noted that short record lengths and inadequate resolution of current climate models in representing small island states limit the assessment of changes in Caribbean extremes.

An analysis of extremes is particularly important for Small Island Developing States (SIDS) like the Caribbean as a region and individual islands develop and implement disaster risk management, mitigation, and adaptation strategies to build resilience against the adverse effects of climate change. The SIDS have been identified among the most vulnerable groups given their relatively small sizes; limited natural and human resources; densely populated coastal, urban, and lowlying areas; remoteness; dependence on high-risk industries such as tourism and offshore banking; and high external transport costs, high public debt, and limited hazard forecasting capabilities $[19,20]$. Extreme events like the severe droughts in 1997 and 2009 through 2010 and their impacts on water resources, agriculture, ecosystems, and tourism highlight the need for improvements in short and long term prediction capabilities of extremes within the region.

The objective of this study therefore is to extend the analysis of future Caribbean climate extremes. This is accomplished by (i) providing $50 \mathrm{~km}$ spatial representation of a subset of climate change indices relevant to the Caribbean; (ii) providing a range of extremes under medium high emissions (A2) and low emissions (B2) scenarios; and (iii) evaluating the extremes along rainfall zones identified for the Caribbean and as such highlighting subregional variability. The trend analysis of future extremes is similar to the work presented for South America by [21] using the PRECIS model output. The subregional approach is explored since previous studies suggest that the Caribbean is characterized by subregions exhibiting slightly differing annual cycles and interannual variability (see [22-26]). Reference [27] suggests 4 zones that define subregional variability. These zones are adopted in the analyses presented in this paper and an additional zone is included to accommodate an expanded observation dataset compared to that used by [27] (see Figure 1). The additional zone incorporates Trinidad and Northern Guyana

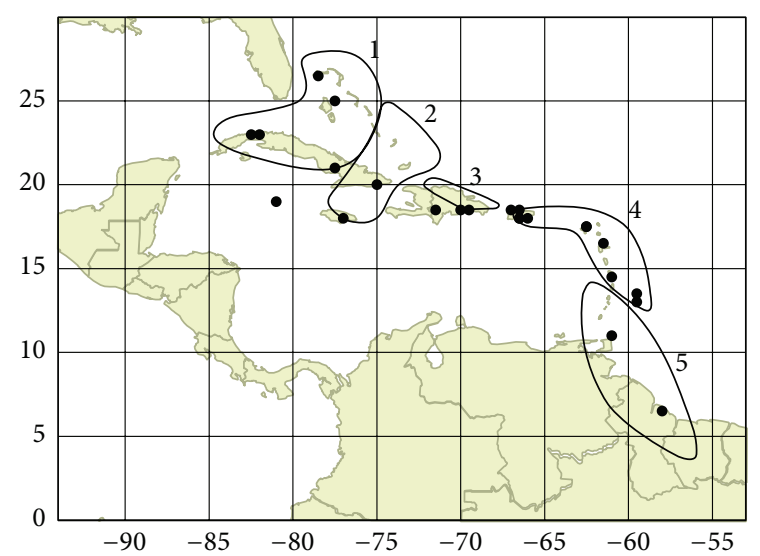

FIgURE 1: Five rainfall zones over the Caribbean and neighbouring regions. Observational weather stations used in this study are also shown.

(zone 5) and is characterized by a double peak in rainfall with maxima in summer and November related to the movement of equatorial trough or Intertropical Convergence Zone, tropical waves moving westward, and upper level systems. Reviews of other Caribbean subregional seasonal rainfall patterns are presented by $[14,28]$.

The paper is organized as follows. Section 2 describes observed trends in daily and extreme rainfall and temperature over the Caribbean. Section 3 presents the methodology and data and Section 4 model validations. Section 5 discusses the projections and Section 6 summarizes findings and suggests some next steps in the analyses of future Caribbean rainfall and temperature extremes.

\section{Observed Trends in Caribbean Climate Extremes}

One of the fundamental studies describing Caribbean climate extremes (or large departures from a mean climate state) is described in [29]. They used a subset of indices from the joint World Meteorological Organization Commission for Climatology (CCI)/World Climate Research Programme (WCRP) Project on Climate Variability and Predictability (CLIVAR) Expert Team on Climate Change Detection and Indices (ETCCMDI). The results were averaged over the Caribbean for a 1958-1999 base period and indicated significant increases in the frequency of warm days and nights, decreases in the frequency of cool days and nights, decreasing number of maximum consecutive dry days annually, and increasing frequency of heavy rainfall events. These are consistent with the global surveys of $[30,31]$.

A second data workshop was held at the University of the West Indies, Jamaica, in May 2012. Trends in daily and extreme temperature and precipitation indices in the Caribbean region were evaluated for the 1961-2010 and 19862010 periods over rainfall zones. The analyses suggest that annual means of the daily minimum and maximum temperatures have increased, with minimum temperatures showing stronger warming. The frequency of warm days, warm 
nights, and extreme high temperatures has increased while fewer cool days, cool nights, and extreme low temperatures were found for both periods. Precipitation trends were less consistent and generally weak. Small positive trends were found in annual total precipitation, daily intensity, maximum number of consecutive dry days, and heavy rainfall events particularly during the period 1986-2010 [28].

The two data workshops held in the Caribbean are similar to workshops held globally aimed at analyzing observed changes in climate extremes. For example, workshops have been held in countries in the western Indian Ocean [32], South America [33-36], parts of Africa [37, 38], the Middle East [39], Central and South Asia [40], Southeast Asia and South Pacific [41, 42], and the Arab region [43]. In the same way that these analyses provide a consistent methodology for comparison of observations globally $[43,44]$ the approach also provides a framework for the assessment of the skill of global and regional models in simulating present day climate extremes over different regions. Additionally model projections of these standard extreme metrics can be compared globally to obtain coherent pictures of future change [45].

Other observed climate trends for the Caribbean include a modest but statistically significant drying trend for the Caribbean's summer period in recent decades [46]; declines in annual rainfall totals by $250 \mathrm{~mm}$ since 1900 [47]; decreasing early (May-July) and late (August-October) season precipitation with marked negative trend commencing in 1960 [48]; declining rainfall in the central Caribbean with an increasing trend in stations in Nassau and Maracaibo $[13,49-51]$; and an increase in temperature exceeding $0.5^{\circ} \mathrm{C}$ since 1900 [47]. See reviews in [52, 53]. A useful model should be able to represent a number of these trends with reasonable skill and therefore provide useful information on future changes.

\section{Data and Methodology}

3.1. Observation Data. Daily observation data were obtained from 23 meteorological stations across the Caribbean as well as neighbouring countries such as Guyana. These countries are member states of the Caribbean Community (CARI$\mathrm{COM}$ ). Stations are listed in Table 1 and their distribution is shown in Figure 1.

The data were compiled from the regional climate change workshops held for the Caribbean in 2001 and 2012 and are complemented by data obtained from the Caribbean Institute for Meteorology and Hydrology (CIMH) and the National Climatic Data Center (NCDC). Data quality and homogeneity have been assessed using the RClimDex (version 1.0) QC and RHTests (version 3.0) data homogenization tools provided by the ETCCDI. The software tools were applied using the freely available R statistical package. Software and documentation are available at http://etccdi.pacificclimate.org/. Details on the quality control procedures and homogeneity tests applied are outlined in $[22,28]$. Some of their quality control procedures include corrections for negative values of precipitation or minimum temperatures higher than maximum temperatures. Erroneous precipitation was always replaced with missing values. Similarly, highly improbable values of either maximum or minimum temperature or both were removed. A subset of the data was used and spans 19791989 to overlap with the period for which model output is available.

3.2. Model Data. Modelled daily maximum and minimum temperatures and precipitation values were obtained from the Hadley Centre's PRECIS RCM. The PRECIS model is a dynamical downscaling atmospheric and land surface model which simulates climate at a minimum and maximum horizontal resolution of 50 and $25 \mathrm{~km}$, respectively. This study makes use of simulations at the $50 \mathrm{~km}$ resolution which were the only experiments available for the entire Caribbean and adjacent countries at the time the study was commissioned. The model can be located over any part of the globe and simulates a full range of meteorological variables at up to 19 levels of the atmosphere and surface variables at varying timescales. Model physics is described in $[54,55]$. The PRECIS model has been widely used to develop regional climate change scenarios worldwide and to study climate extremes. See, for example, [21, 56-62]. The PRECIS model has also been validated with respect to Caribbean climatology by $[5,63]$. Simulations that have been undertaken using the PRECIS model have been part of a regional initiative known as the PRECISCaribbean Project that seeks to generate dynamically downscaled climate change information for the Caribbean region. A detailed overview of the project is described by [1].

This study uses data obtained from 4 experiments set up over a domain of $0^{\circ}-36^{\circ} \mathrm{N}$ and $55^{\circ}-120^{\circ} \mathrm{W}$. The experiments were (i) PRECIS forced at its lateral boundaries by the ERAreanalysis data for 1979-1993; (ii) PRECIS forced at its lateral boundaries by the Max Planck Institute ECHAM5 GCM for the 1961-1989 time slice; and (iii) PRECIS forced by the ECHAM5 GCM under the SRES A2 and B2 emissions scenarios for 2071-2099.

3.3. Indices. A subset of the suite of ETCCDI climate change indices considered relevant to the region are used in this study. Calculations were performed using the RClimDex software package to provide consistency with climate change studies executed globally. Nine indices are investigated in this study, four of which relate to temperature. These indices represent moderate extremes, that is, those that occur a number of times each year versus events occurring once every decade, for example. The extreme temperature indices are percentile based. They include warm days (nights), defined as annual count when maximum (minimum) temperature is greater than the 90th percentile, TX90P (TN90P); cool days (nights), defined as the annual count when maximum (minimum) temperature is less than the 10th percentile, TX10P (TN10P).

The precipitation indices include the annual maximum number of consecutive dry and wet days (CDD and CWD), that is, days with rainfall below and above $1 \mathrm{~mm}$, respectively, and the number of days with daily rainfall above $10 \mathrm{~mm}$ (R10). The maximum 5-consecutive-day precipitation (RX5day) and heavy rainfall amounts, that is, annual total rainfall when amounts are above the 95th percentile (R95P), are also investigated. Annual indices were computed if no more than 15 days were missing during the year, and percentiles were 
TABLE 1: List of observation station data.

\begin{tabular}{|c|c|c|c|c|c|c|c|c|}
\hline \multirow{2}{*}{ Country } & \multirow{2}{*}{ Station name } & \multicolumn{3}{|c|}{ Coordinates (degrees) and Elevation (metres) } & \multicolumn{3}{|c|}{ Percentage available data for 1979-1989 } & \multirow{2}{*}{ Zone } \\
\hline & & Latitude (N) & Longitude (W) & Elevation & PRCP & $T_{\mathrm{Max}}$ & $T_{\text {Min }}$ & \\
\hline Bahamas & Freeport & 26.55 & -78.7 & 11 & 100 & 100 & 100 & 1 \\
\hline Bahamas & Nassau Airport & 25.05 & -77.47 & 7 & 87 & 98 & 98 & 1 \\
\hline Barbados & $\mathrm{CIMH}$ & 13.15 & -59.62 & 112 & 100 & 98 & 98 & 4 \\
\hline Barbados & GAIA & 13.06 & -59.48 & 56 & 100 & 94 & 94 & 4 \\
\hline Cayman & Grand Cayman & 19.17 & -81.21 & 3 & 98 & 95 & 95 & - \\
\hline Cuba & Guantanamo Bay & 19.9 & -75.15 & 16 & 100 & 100 & 100 & 2 \\
\hline Cuba & Camaguey & 21.24 & -77.51 & 124 & 100 & 100 & 100 & 1 \\
\hline Cuba & Casablanca & 23.1 & -82.21 & 51 & 100 & 100 & 100 & 1 \\
\hline $\begin{array}{l}\text { Dominican } \\
\text { Republic }\end{array}$ & Jimani & 18.29 & -71.51 & 31 & 100 & 99 & 99 & - \\
\hline $\begin{array}{l}\text { Dominican } \\
\text { Republic }\end{array}$ & Las Americas & 18.26 & -69.4 & 14 & 100 & 100 & 99 & 3 \\
\hline $\begin{array}{l}\text { Dominican } \\
\text { Republic }\end{array}$ & Santo Domingo & 18.28 & -69.52 & 14 & 100 & 100 & 100 & 3 \\
\hline Guadeloupe & Le Raizet & 16.27 & -61.6 & 11 & 100 & 100 & 100 & 4 \\
\hline Guyana & Georgetown & 6.5 & -58.13 & 0 & 100 & 98 & 99 & 5 \\
\hline Jamaica & Worthy Park & 18.15 & -77.15 & 350 & 99 & 89 & 97 & 2 \\
\hline Martinique & Lamentin & 14.59 & -60.99 & 3 & 100 & 100 & 100 & 4 \\
\hline Puerto Rico & Lares & 18.27 & -66.85 & 445 & 100 & 0 & 0 & - \\
\hline Puerto Rico & Ponce & 18.02 & -66.52 & 21 & 99 & 99 & 99 & 4 \\
\hline Puerto Rico & San Juan WSFO & 18.43 & -66.6 & 3 & 100 & 100 & 100 & 4 \\
\hline Puerto Rico & Utuado & 18.25 & -66.68 & 159 & 100 & 99 & 99 & - \\
\hline Puerto Rico & Maunabo & 17.98 & -65.88 & 33 & 100 & 92 & 91 & 4 \\
\hline St. Kitts & Olivees & 17.37 & -62.82 & 143 & 99 & 0 & 0 & 4 \\
\hline St. Kitts & Wingfield & 17.35 & -62.8 & 56 & 99 & 0 & 0 & 4 \\
\hline Tobago & Crown Point & 11.15 & -60.84 & 3 & 100 & 98 & 98 & 5 \\
\hline
\end{tabular}

calculated if no more than $10 \%$ of values were missing in the reference periods.

3.4. Methodology. The extreme indices were first calculated over the 1979-1989 period for each station (see Table 1) and for each grid point over a Caribbean island and Guyana in the ERA-reanalysis driven PRECIS data. Linear trends are fitted to each index using the ordinary least squares regression and the statistical significance of the trends is assessed at the 5\% level using the $t$-test. Maps of trend values were constructed for observations and model data and compared for each of the nine indices. Points with statistically significant trends are indicated on maps and rainfall zones are also superimposed.

Areal averages of trend values are calculated over each zone for each of the indices for the two datasets. The comparison allows the determination of the model skill in representing trends associated with each index. Regional trends deduced from the model were constructed in two ways: (i) using all grid points falling in the zone and (ii) using only those grid points corresponding to the coordinates of a station. The analysis allows us to determine whether the regional trends are sensitive to the number of grid points used in the calculation. It is useful to note that there are 23 stations/points with rainfall observations and 20 points with temperature in comparison to 229 PRECIS points that are available over land. For temperature, averages were also calculated over the entire domain for observations and for model and compared.

The difference in the regional trends between observations and their model counterparts was assessed statistically using the Student $t$-test for the 95\% level for each zone and for the Caribbean. Additionally the correlation coefficient was calculated between regional extreme indices derived from the observations and those derived from the model (constructed using corresponding grid boxes) for each zone. The significance of the correlation is assessed used the Ebisuzaki method which accounts for serial correlation [64].

Limitations of the methodology relate to sparseness of station data, the relatively short period used for the validation of the model, the scale mismatch between the station point locations and the gridded dataset, and the limited number of model realizations. A scarcity of daily climate data continues to be a challenge in the Caribbean. Though a number of initiatives are currently underway that in some way address this problem, the issue lingers and limits the degree of validation that may be accomplished in this study. Secondly the period used for validation is 11 years and represents an optimal tradeoff between period of overlap and number of available 
stations. However, our aim is to ascertain the skill of the PRECIS in simulating the variability and trends of observed extremes over a specified period rather than to categorically characterize present day extremes as done by studies noted in Section 2. In this respect the period of analysis though short may be deemed sufficient. The authors have also examined validating the model by comparing ECHAM forced PRECIS baseline with observations over the 1973-1989 period. (This is as opposed to analyzing the ERA-reanalysis driven PRECIS data as reported in in this study.) We find that either approach is legitimate and provides sufficient evidence of the model biases with respect to present climate extremes. Therefore the latter approach is not discussed in detail in this paper. The scale mismatch arises since the station data represents information at a specific location whereas the grid value represents an area mean. To minimize biases relating to scale mismatch, one approach is to use mean over a number of sites in the region before comparison with model data as is also being used in this study. Finally we note that only one realization under the $\mathrm{A} 2$ and $\mathrm{B} 2$ scenarios is available for analysis. Ideally a number of ensemble members under each scenario would have been useful in quantifying the model uncertainty in simulating future extremes. A detailed discussion on the analysis of extremes is presented in the guidance document prepared by [45].

Subsequent to the validation of the PRECIS model for present day extremes, indices were also calculated using the model data from the ECHAM forced PRECIS experiments for the 1961-1989 and 2071-2099 periods. Changes in "future" trends relative to 1961-1989 are normalized for spatial representation across the $\mathrm{A} 2$ and $\mathrm{B} 2$ scenarios and the mean absolute changes in trends are presented for each zone. Normalized values are obtained by dividing the absolute change for each grid point by the largest trend value (ignoring sign) across the A2 and B2. This is to allow for ease of comparison across scenarios. The significance of the 2071-2099 slope values is also assessed at the $5 \%$ level using the $t$-test.

\section{Validation of Current Trends in Extreme Climate Indices}

Validation of the PRECIS RCM was achieved by comparing the model representation of current extremes with station data spatially and temporally using an 11-year data slice (19791989). Temporal variability is compared over zones and over the entire domain for temperature.

4.1. Rainfall Trends. Figures 2 and 3 show the validation maps for the maximum number of consecutive dry days (CDD) and annual total precipitation when rainfall is greater than the 95th percentile (R95P), respectively, over the 1979-1989 period. A useful guide to the analysis is that zones 1-3 are the northernmost zones, zone 4 is largely the eastern Caribbean, and zone 5 is the southern zone.

Although it is difficult to compare the spatial representation of the indices due to the sparse observation data, there is some consistency between the model and some observation locations. This is observed with respect to an increase in CDD in zone 1 (Casablanca, Cuba) and zone 4 (Lamentin, Martinique and CIMH, Barbados). Interestingly the model simulates positive trends in CDD for most of zones 1-5. On the other hand the maximum number of consecutive wet days (CWD) appears to be spatially well represented with respect to the sign of the trends over each zone. This involves positive and negative trends in zones 1 and 4 and negative trends in zones 2, 3, and 5 (not shown), that is, trend directions largely opposite to CDD. There is agreement as well with respect to extreme rainfall events (R95P) and the negative (positive) trends represented over zones 1, 2, 3, and 4 (zone 5: Crown Point, Tobago, and Georgetown, Guyana) (Figure 3). However, the model does not represent the annual maximum 5-day rainfall totals (RX5) very well except for some locations in zones 2 (not shown). In this zone an increase over Jamaica and decreases over southern Cuba are simulated well by the model. The decreases in wet days (R10) observed in zones 2 and 4 and a station in Cuba (zone 1) and increase in Trinidad (zone 5) are also represented by the model (not shown).

Model representation of the yearly CDD time series coincides with a number of observed values for each of the five zones although correlations suggest that the observed year-to-year variability is not well represented by the model (see Figure 2) except for zone 5 where the correlation is as much as 0.64 and statistically significant. The trend values shown in Table 2 suggest that model captures the direction of the CDD trend for 3 of the 5 zones with only zone 2 suggesting that the difference in the value of the trends was statistically significant. Observed and model CWD trends of the same sign were obtained for 2 of the 5 zones though the difference in the trends was only statistically significant for zone 2. However there is a tendency to underestimate the annual count of days when precipitation is greater than or equal to $10 \mathrm{~mm}$ (not shown), the annual total precipitation when rainfall is greater than the 95th percentile (R95), and the annual maximum consecutive 5 -day precipitation (RX5) (not shown) even though there is some consistency in the yearly variability. The direction of the trends is similar for 2 of the 5 zones for R95P and RX5 with no clear pattern in the biases in these cases. For the R95P (RX5) zones 2 and 4 ( 1 and 3 ) show decreases (see Table 2 ) though in many cases the differences in trends are not statistically significant. The directions of trends for R10 are oppositely signed for most of the zones analyzed though the differences are statistically significant for only one zone. The suggestion is that the model does a better job simulating consecutive wet days and very wet days than it does with CDD, R10, and RX5.

4.2. Temperature. For the period of validation most stations indicate a decrease in the frequency of cool nights (TN10P). The model simulates some decrease but also simulates increases over much of the domain. Additionally the model simulates a decrease in the frequency of warm nights (TN90P) as indicated for most stations (Figure 4). Figure 5 suggests that, over the 1979-1989 period, there has been a decrease in the number cool days (TX10P) with increases observed over the eastern islands. An increase in the number of warm days (TX90P) over some northern locations and 

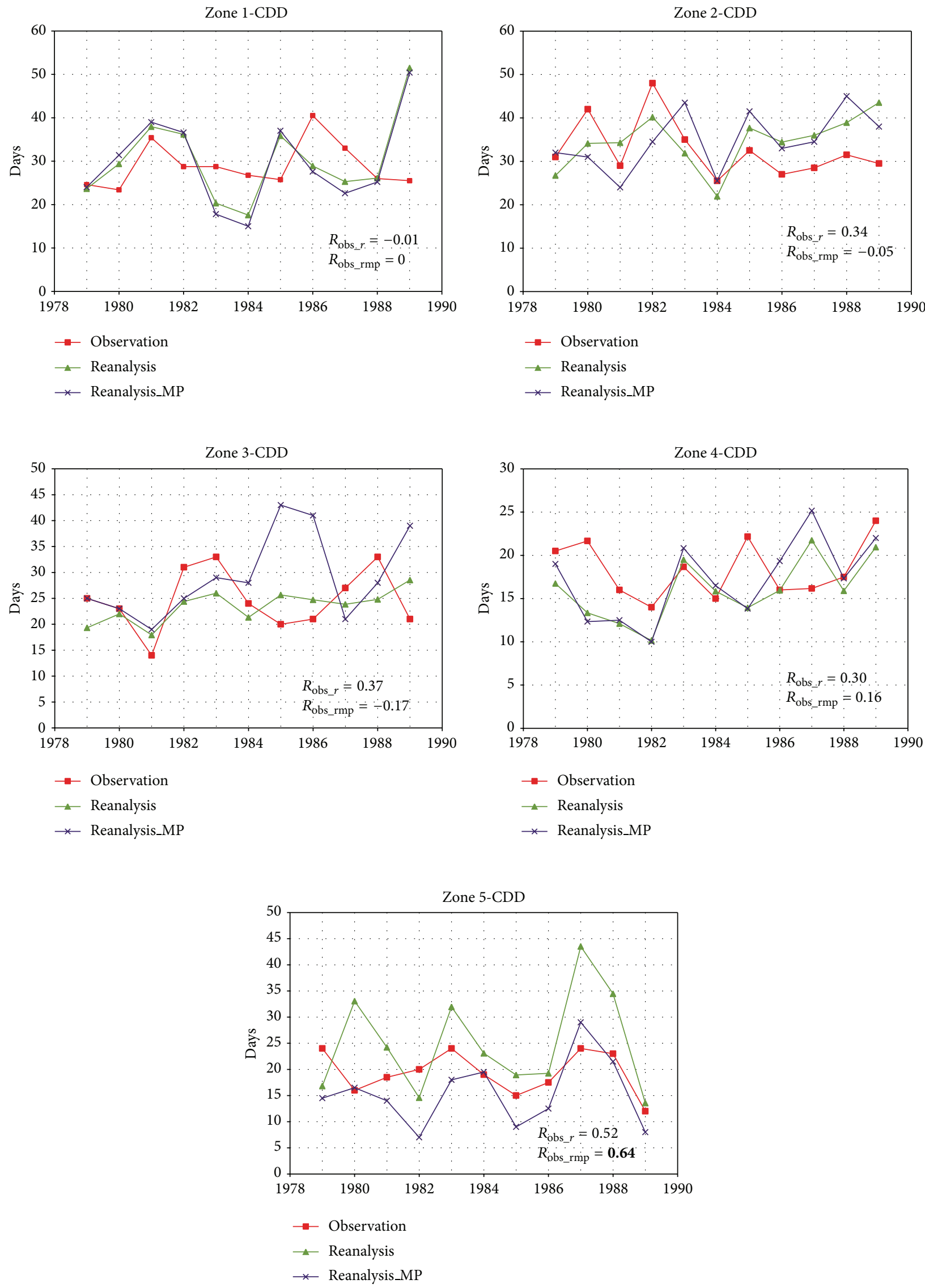

(a)

FIgure 2: Continued. 


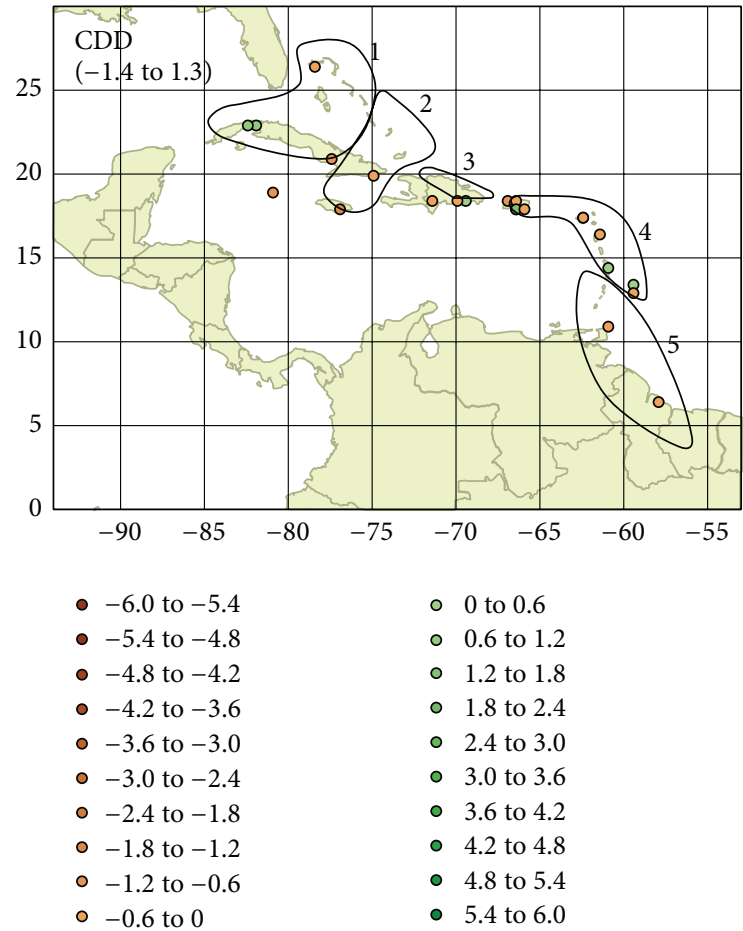

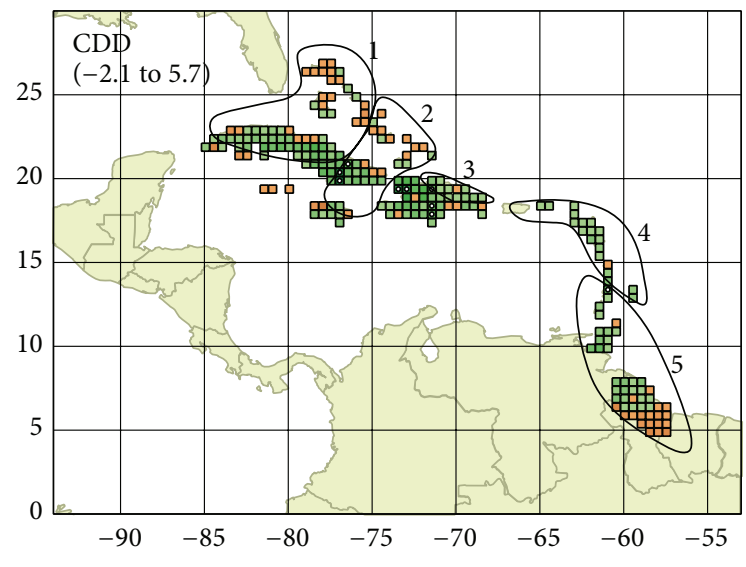

- -6.0 to -5.4

- -5.4 to -4.8

- -4.8 to -4.2

- -4.2 to -3.6

- -3.6 to -3.0

- -3.0 to -2.4

- -2.4 to -1.8

- -1.8 to -1.2

- -1.2 to -0.6

- -0.6 to 0
- 0 to 0.6

0.6 to 1.2

- 1.2 to 1.8

- 1.8 to 2.4

- 2.4 to 3.0

- 3.0 to 3.6

- 3.6 to 4.2

- 4.2 to 4.8

- 4.8 to 5.4

- 5.4 to 6.0

(b)

FIGURE 2: Temporal and spatial variability of consecutive dry days (CDD). Graphs show average time series for each zone for observation (red), PRECIS-reanalysis (green), and reanalysis matching points (purple) for 1979-1989. Correlation coefficients between the observation time series and each reanalysis time series are noted with values in bold indicating statistical significance at the 95\% level. Maps of observed trends (left) and PRECIS-reanalysis trends (right) for 1979-1989 are shown in the bottom panel. Trend units are days/year. Brown colour indicates negative and green colour indicates positive trends. Statistically significant trends are indicated with white stippling.

TABLE 2: Linear trends calculated over 1979-1989 for station observations (OBS) and PRECIS-reanalysis matching points (RMP) for all indices across each zone and the entire Caribbean. Trend values with differences that are statistically significant at the $95 \%$ level are in bold and italics. CDD (CWD) is the maximum number of consecutive dry (wet) days; R10 is the annual count of days when precipitation is greater than or equal to $10 \mathrm{~mm}$; R95P is the annual total precipitation when rainfall is greater than the 95th percentile; RX5 is annual highest 5-consecutiveday precipitation (mm); TX90 (TN90) is the percentage of days when maximum (minimum) temperature is greater than the 90th percentile; TX10 (TN10) is the percentage of days when maximum (minimum) temperature is less than the 10th percentile.

\begin{tabular}{|c|c|c|c|c|c|c|c|c|c|c|c|c|c|c|}
\hline \multirow{2}{*}{ Zones } & & \multicolumn{2}{|c|}{1} & \multicolumn{2}{|c|}{2} & \multicolumn{2}{|c|}{3} & \multicolumn{2}{|c|}{4} & \multicolumn{2}{|c|}{5} & \multicolumn{2}{|c|}{ All } & \multirow{2}{*}{ Units/year } \\
\hline & & OBS & RMP & OBS & RMP & OBS & RMP & OBS & RMP & OBS & RMP & OBS & RMP & \\
\hline \multirow{9}{*}{ Indices } & $\mathrm{CDD}$ & 0.26 & 0.54 & -0.87 & 1.02 & 0.24 & 1.29 & 0.08 & 0.77 & -0.27 & 0.31 & -0.06 & 0.60 & days \\
\hline & CWD & -0.01 & 0.51 & 0.01 & -0.85 & -0.12 & -0.65 & 0.06 & 0.00 & -0.12 & 0.81 & -0.02 & 0.12 & days \\
\hline & R10 & 0.98 & -1.13 & 0.24 & -1.12 & 0.52 & -0.31 & -0.58 & -1.68 & -0.20 & 0.49 & -0.11 & -0.94 & days \\
\hline & R95P & 6.41 & -34.67 & -12.45 & -12.56 & 10.76 & -5.86 & -3.19 & -19.44 & 16.93 & -0.63 & 3.39 & -19.13 & $\mathrm{~mm}$ \\
\hline & RX5 & -2.26 & -12.44 & 3.84 & -1.67 & -8.77 & -0.87 & 4.62 & -3.44 & 0.69 & -0.77 & 1.37 & -5.13 & $\mathrm{~mm}$ \\
\hline & TN10P & -0.15 & 0.09 & -0.25 & 0.02 & -0.15 & 0.14 & -0.09 & 0.59 & -0.18 & 0.42 & -0.14 & 0.30 & $\%$ \\
\hline & TN90P & 0.15 & -0.08 & 0.41 & 0.11 & 0.30 & -0.17 & -0.03 & -0.48 & 0.28 & -0.39 & 0.16 & -0.29 & $\%$ \\
\hline & TX10P & -0.06 & 0.01 & -0.75 & -0.20 & 0.44 & 0.01 & 0.11 & 0.55 & -0.08 & 0.40 & -0.05 & 0.26 & $\%$ \\
\hline & TX90P & 0.07 & -0.02 & 0.36 & 0.13 & -0.83 & -0.07 & 0.04 & -0.30 & 0.09 & -0.21 & 0.04 & -0.18 & $\%$ \\
\hline
\end{tabular}

decrease over the eastern Caribbean have also been observed. The model does reasonably well in simulating the spatial variability of these trends.

Further investigation of temperature trends involved the creation of regional and Caribbean-wide average indices from the observation and model data. The model averages presented in Figures 4 and 5 were constructed using (i) only the grids corresponding to station coordinates ( $\mathrm{rmp}$ ) and (ii) all the gridded data within zones $(r)$. Figure 4 indicates that the model does a very good job of reproducing the temporal variability of cool nights (TN10P) and warm nights (TN90P) with reasonably high statistically significant correlations for warm nights (rmp: 0.65 and $r$ : 0.79). Similarly Figure 5 suggests that the model reproduces variations in cool days 

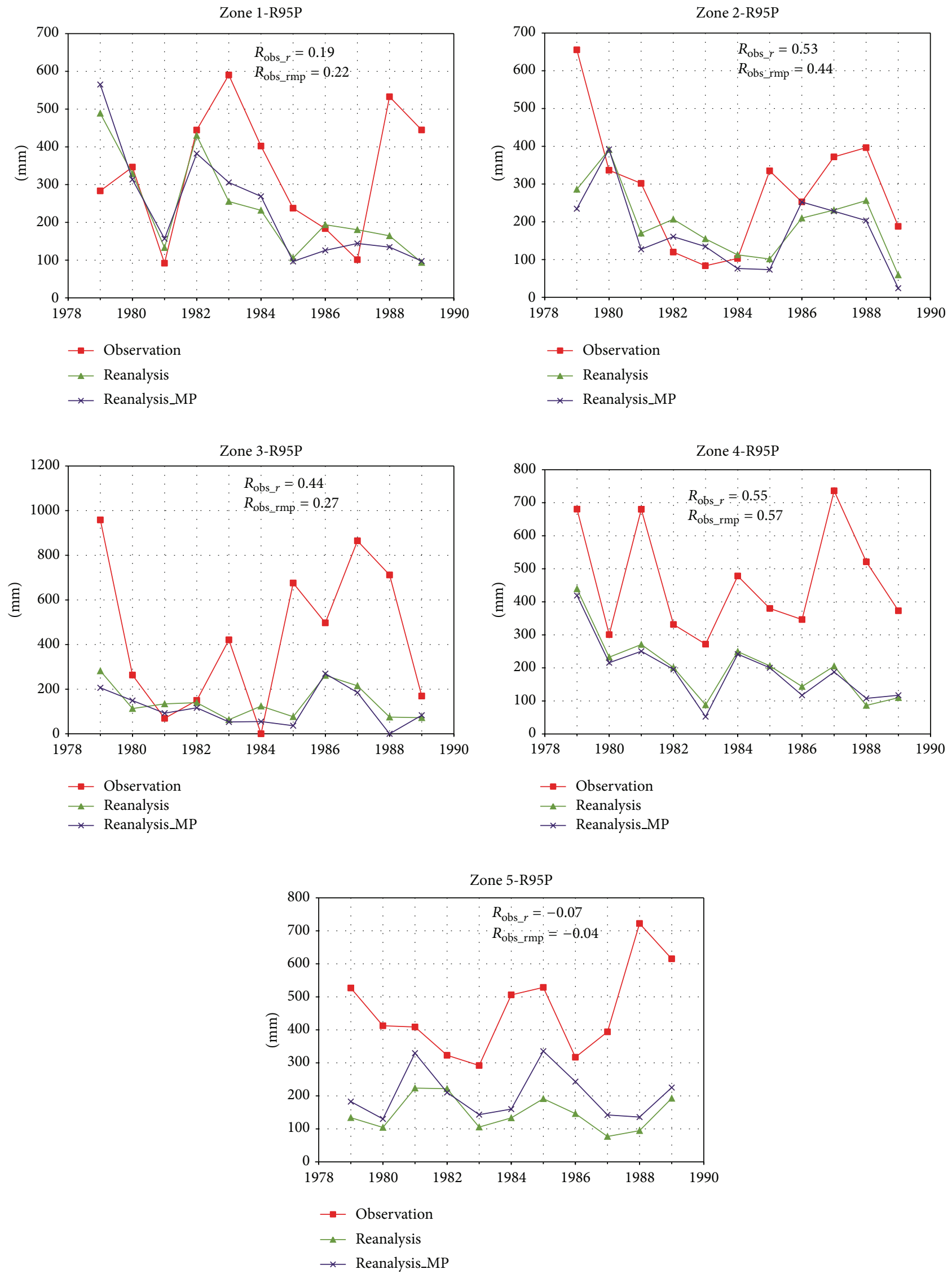

(a)

FIgURE 3: Continued. 

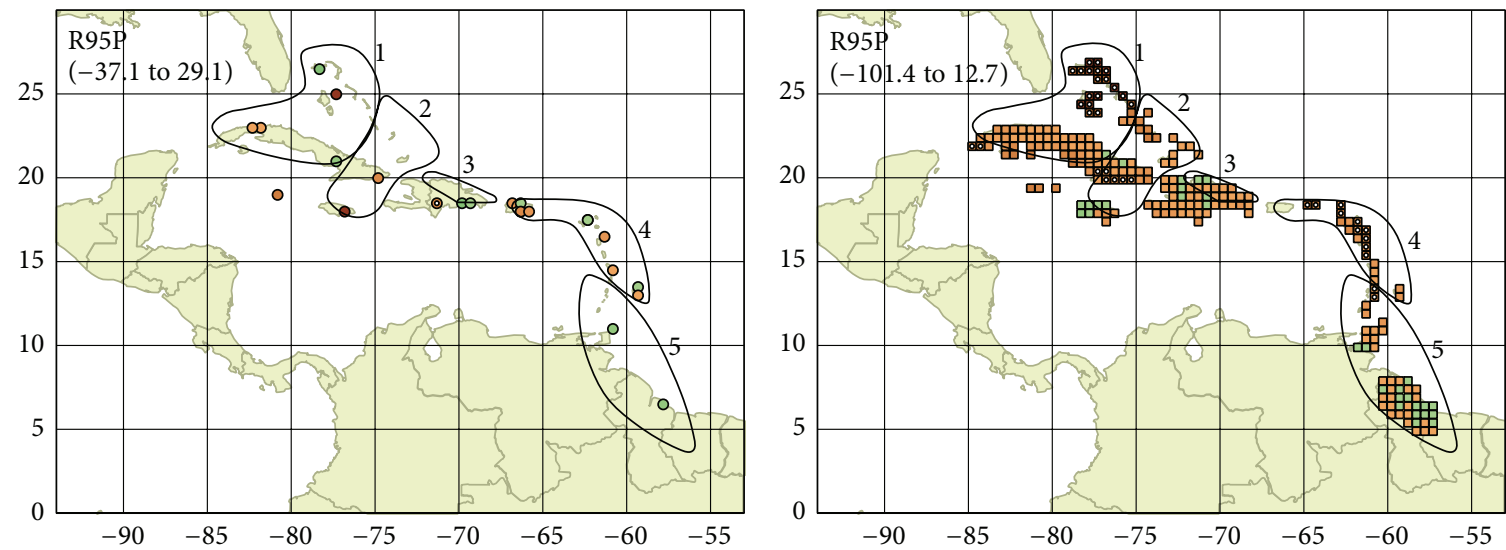

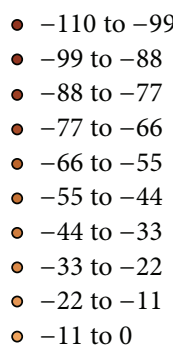

- -11 to 0

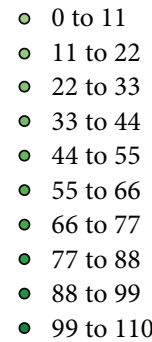

- 0 to 11

44 to 55

55 to 66

77 to 88

- 99 to 110

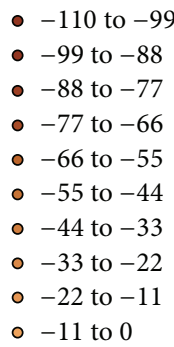

- 0 to 11

- 11 to 22

- 22 to 33

- 33 to 44

- 44 to 55

- 55 to 66

- 66 to 77

- 77 to 88

- 88 to 99

- 99 to 110

(b)

FIgURE 3: The same as Figure 2 but for extreme rainfall (R95P). Units are mm/year. Statistically significant trends are indicated with white stippling.

(TX10P) and warm days (TX90P) very well albeit with some biases. Table 2 shows a comparison of the linear trends for temperature indices over individual rainfall zones as well as averaged across all zones. The trend values for the observation and the model are in most cases oppositely signed due to model biases though statistically not dissimilar. The model performance is the strongest for warm and cool day trends.

\section{Future Projections of Extremes}

To provide a context to the discussion of future projections of climate extremes for the Caribbean and adjacent regions, we briefly review projections of changes in the mean climate under the A2 and B2 scenarios for 2071-2099 derived from the downscaling of the ECHAM4 model [63]. A slight increase in annual rainfall of $0.9 \%$ and $2.9 \%$ for $\mathrm{A} 2$ and $\mathrm{B} 2$, respectively, is projected over the mean Caribbean. The spatial pattern indicates a drying over the Caribbean Sea and parts of Central America of up to 50\% relative to 1961-1989 baseline. Significant dry areas are projected over the Gulf of Mexico with increased rainfall amounts of up to $90 \%$ over the northern part of South America across both emissions scenarios. Temperatures are projected to rise by $3.4^{\circ} \mathrm{C}$ and $2.6^{\circ} \mathrm{C}$ for the $\mathrm{A} 2$ and $\mathrm{B} 2$ scenarios, respectively. The warming trends projected are significant over land areas and to a lesser extent over the sea and display an east-west gradient in the distribution of temperatures with greater warming over the eastern Caribbean. This is particularly evident during the dry season (November-January). The largest warming is evident in the wet season (May-November).

5.1. Rainfall. Normalized changes in trends in rainfall extremes for 2071-2099 relative to 1961-1989 vary across the Caribbean for the IPCC SRES A2 and B2 scenarios (Figure 6). In order to adequately classify the absolute changes within zones, Figure 8 is also constructed to show the mean change over each zone for each index. It is useful to note that a positive (negative) change in indices such as maximum number of consecutive wet days (CWD), the annual count of days when precipitation is greater than or equal to $10 \mathrm{~mm}$ (R10), the annual total precipitation when rainfall is greater than the 95th percentile (R95P), and the annual maximum consecutive 5-day precipitation (RX5) suggest a tendency towards wetter (drier) conditions relative to present day. The converse is true for the maximum number of consecutive dry days (CDD) in that positive (negative) changes indicate a shift towards drier (wetter) conditions. Similarly a positive (negative) change in warm days (TX90P) and warm nights (TN90P) suggests warmer (cooler) conditions relative to the present. The converse is true for cool days (TX10P) and cool nights (TN10P); that is, positive (negative) changes suggest cooler (warmer) conditions.

There is weak consensus with respect to mean changes in CDD, CWD, and R10 across the A2 and B2 scenarios for zones $1-4$. Figure 8 suggests slight decreases in the mean frequency 

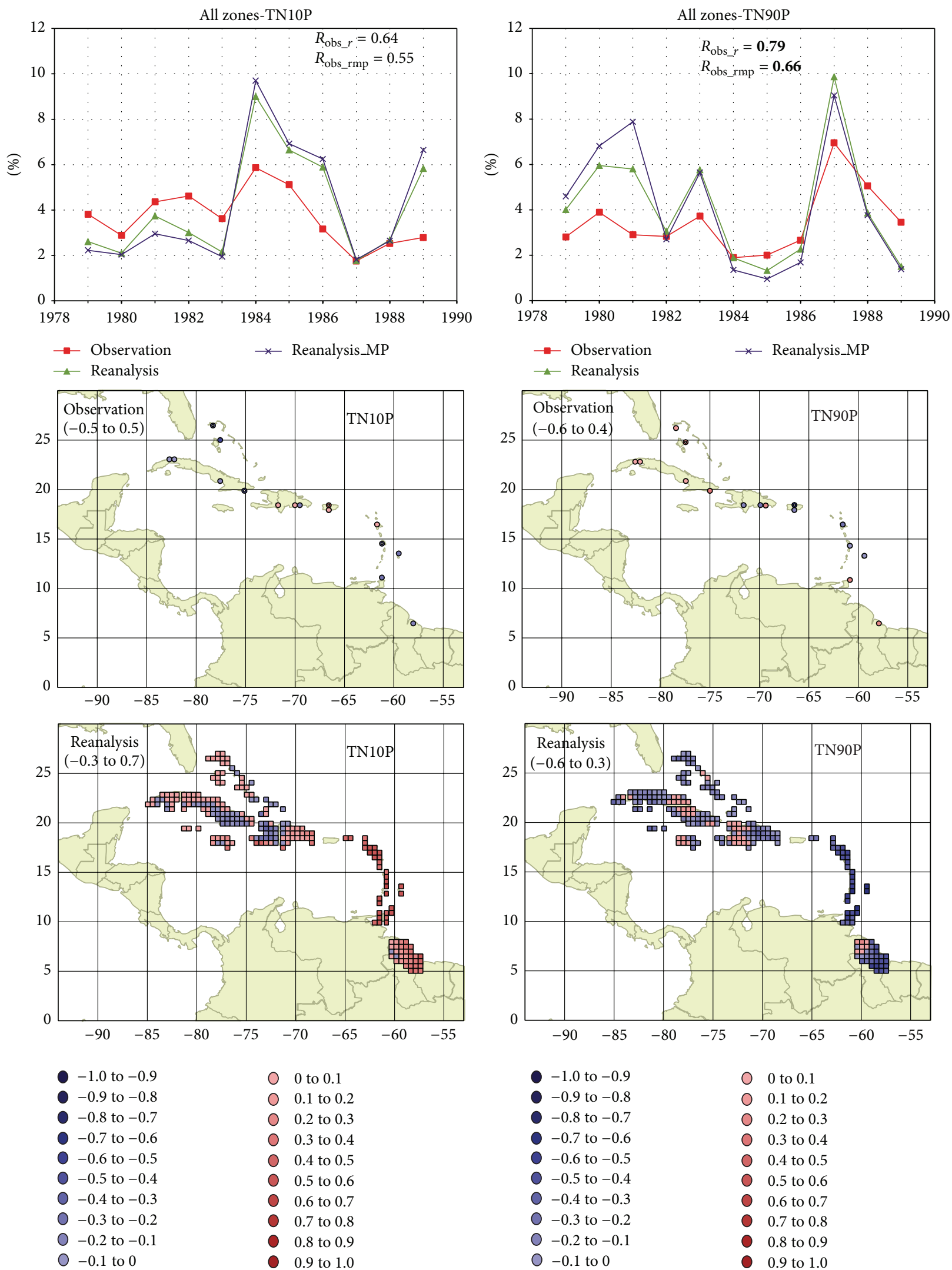

0 to 0.1

○ 0.1 to 0.2

O 0.2 to 0.3

0.3 to 0.4

○ 0.4 to 0.5

0.5 to 0.6

0.6 to 0.7

0.7 to 0.8

0.8 to 0.9

- 0.9 to 1.0

FIGURE 4: Temporal and spatial variability of cool nights (TN10P) and warm nights (TN90P). Graphs show average time series for entire domain for observation (red), PRECIS-reanalysis (green), and reanalysis matching points (purple) for 1979-1989. Maps of observed trends and PRECIS-reanalysis trends for 1979-1989 are shown in the middle and bottom panels, respectively. Blue colour indicates negative and red colour indicates positive trends. Statistically significant trends are indicated with white stippling. 

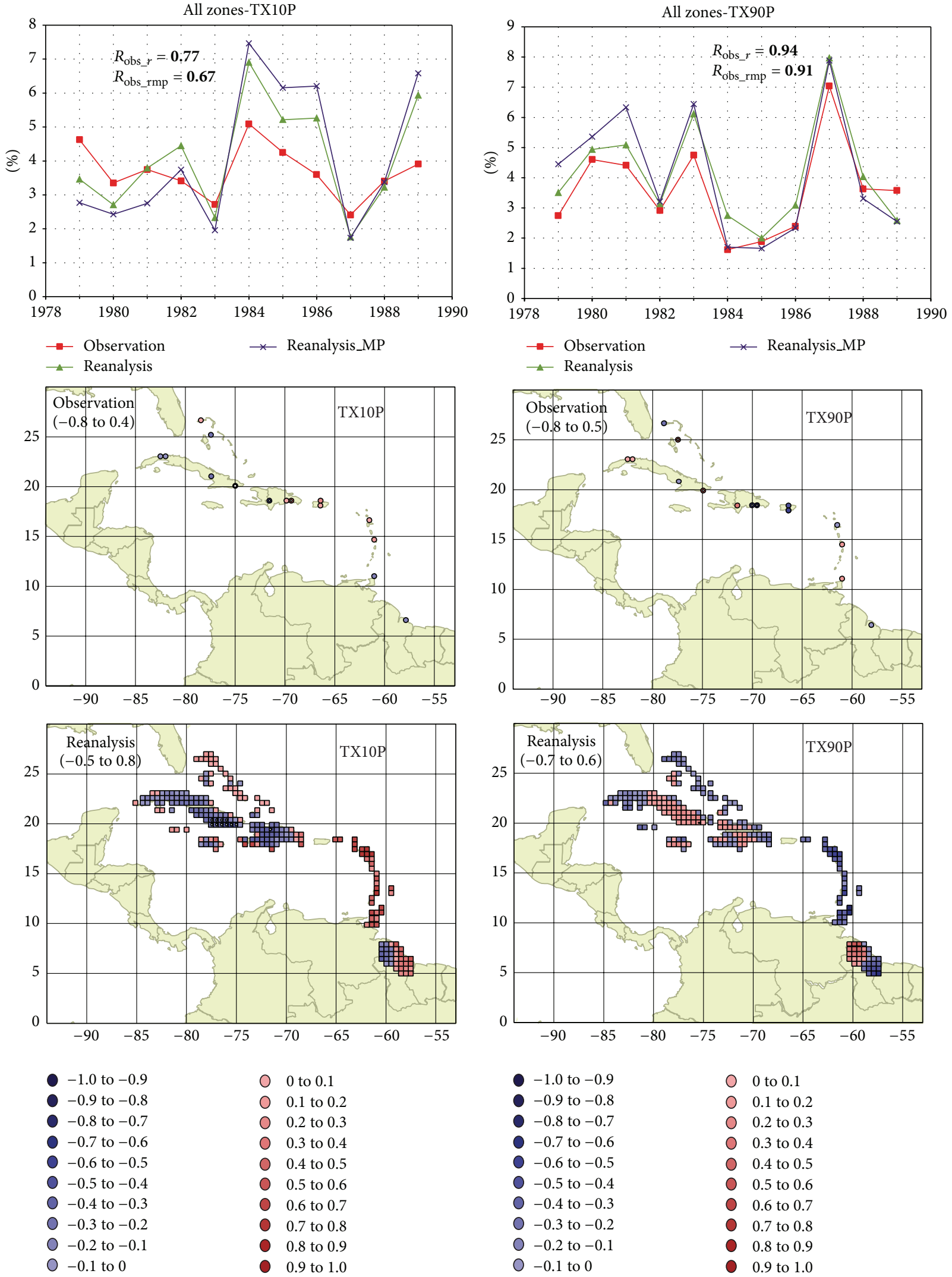

FIGURE 5: The same as Figure 4 but for cool days (TX10P) and warm days (TX90P). Statistically significant trends are indicated with white stippling. 

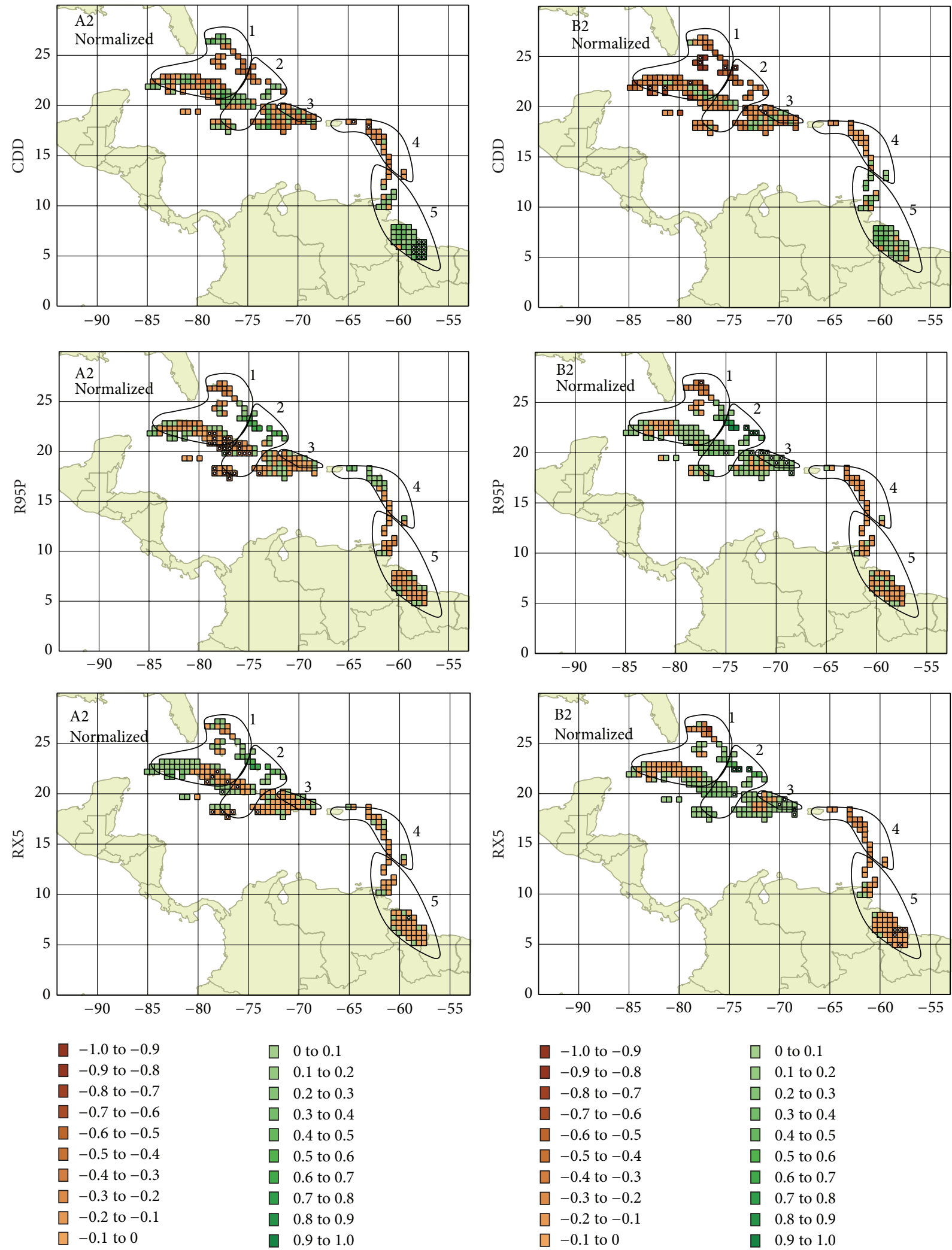

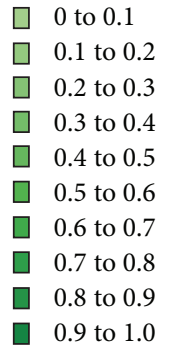

(a)

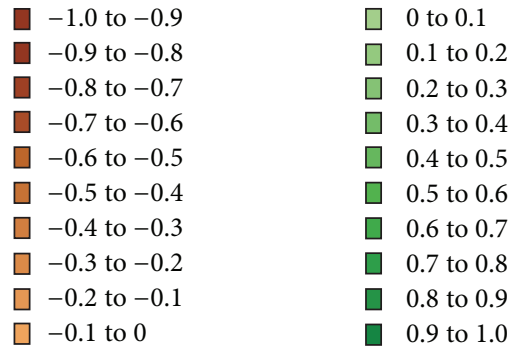

(b)

FIGURE 6: Projected normalized changes in trends for CDD, R95P, and RX5 for 2071-2099 relative to 1961-1989 for the A2 (left panels) and B2 (right panels) IPCC SRES Scenarios. Brown colour indicates negative and green colour indicates positive trends. Statistically significant trends are indicated with white stippling. 
of consecutive dry days (up to -0.3 days/year under B2), slight increases in the mean frequency of consecutive wet days $(+0.1$ days/year under A2 and B2), and slight increases in the mean frequency of wet days $(+0.1$ days/year for B2). For the same zones, there appears to be a stronger indication across the scenarios of increases in extreme rainfall (up to $+1.9 \mathrm{~mm} /$ year under A2 and $+4.5 \mathrm{~mm} /$ year under B2) and increases in maximum 5 -day rainfall (up to $+1.1 \mathrm{~mm} /$ year and $+2.2 \mathrm{~mm} /$ year under A2 and B2, resp.). Some exceptions for mean increase in wet day frequency and extreme rainfall are evident for zone 1 under A2 and zone 4 under B2, where a mean decrease of 0.1 days/year and up to $1.4 \mathrm{~mm} /$ year, respectively, is projected. Interestingly the R95P projection for zone 1 is counter to the statistically significant positive trend recorded over a slightly modified zone 1 for a 1986-2010 period by [28] but is consistent for zone 2 where the most intense projections in R95P and RX5 are noted under both scenarios.

For zone 5 projections suggest a slight shift toward drier conditions via a positive change in CDD $(+0.3$ day/year $)$ and negative changes in R10 ( -0.1 days/year) and R95P $(-0.5 \mathrm{~mm} /$ year $)$ under the A2. Similar values are noted under B2. Notably the decrease in R95P is counter to the significant increase noted in the index for a modified zone 5 over a 1986-2010 period [28]. Furthermore the changes noted over northern Guyana for CDD (0.9 days/year) and RX5 ( $-0.2 \mathrm{~mm} /$ year) under the A2 and B2, respectively, are associated with statistically significant projections.

In summary, while differential patterns exist across and within zones, Figures 6 and 8 highlight that the prevailing pattern in the mean under A2 and B2 is a tendency towards more intense rainfall events over zones 1 to 4 , that is, the northern and eastern zones but with less consensus changes in the dry and wet spell lengths. The suggestion for zone 5 is that drier conditions will prevail. This is consistent with the gradient pattern of more (less) intense rainfall and less (more) dry days in the northern (southern) Caribbean from the analysis of 7 RCM grids over the Caribbean from the HadAM3P driven PRECIS experiments [5].

5.2. Temperature. Figures 7 and 8 suggest a statistically significant warming under the A2 scenario towards the end of century across all the extreme temperature indices. Under B2, however, a few locations, for example, over parts of Cuba, suggest cooler conditions. A mean warming is anticipated over each zone via a decrease in the frequency of cool nights (up to $-0.9 \%$ /year for A2 and $-0.5 \% /$ year under B2), decrease in frequency of cool days (up to $-0.8 \% /$ year under A2), increase in frequency of warm days (up to $+0.9 \% /$ year for A2 and $+0.4 \%$ /year under B2), and an increase in frequency of warm nights (up to $+0.7 \%$ /year for A2 and $+0.4 \% /$ year under B2). The strongest changes are generally projected over zone 4 , the eastern zone. Interestingly under the B2, the mean change over 3 of the zones approaches zero for cool day occurrence.

Overall, there is strong evidence from these experiments that, towards the end of the century, the Caribbean will become warmer under both scenarios. The projections are consistent with increases in frequency of warm days and nights and decreases in the frequency of cool days and cool nights observed over the Caribbean over the last six decades
$[28,29]$. The warming is also consistent with the warming projected towards the end of century by the ECHAM4 driven PRECIS [63] and the HadAM3P driven PRECIS simulations [5] as well as GCM studies and extreme analyses conducted by $[15,16]$ under multiple scenarios.

\section{Discussion}

This study assessed the skill of the PRECIS model in simulating present day extremes and examined future projections of extremes towards the end of century. The period of validation was 1979-1989, a decade marked by an anomalously dry Caribbean [29] due to an intensified North Atlantic High $[65,66]$. Consistent with this period, the model simulated the observed negative trends in consecutive wet days (CWD) for zones 1-5 and negative trends in extreme rainfall events (R95P) over zones $1-4$. The model also simulated the observed positive trends in the consecutive dry days (CDD) over some locations in zones 1 and 4 . The study showed in general that the model displayed greater skill at representing consecutive wet days and extreme rainfall events than consecutive dry days, wet days, and maximum 5-day precipitation over 1979-1989.

The model exhibits skill in simulating decreases in the frequency of warm nights (TN90P) over most stations and decreases in the number of cool days (TX10P) with increases observed over the eastern islands. Increases in the number of warm days (TX90P) over some northern locations and decrease over the eastern Caribbean have also been observed. This suggests warmer conditions over the north and cooler conditions over the eastern Caribbean. The dichotomy of temperature trends is plausible as previous work has recorded shifts towards cooler temperatures after 1983 for some Caribbean and Central America stations, for example, in Barbados, Costa Rica, Dominican Republic, Honduras, and Panama [28]. The negative trend in cool nights (TN10P) over some locations is not well simulated by the model.

The prevailing pattern of future projections from the ECHAM driven PRECIS RCM for 2071-2099 under A2 and $\mathrm{B} 2$ relative to the model baseline is a tendency towards more intense rainfall events over zones 1 to 4 , that is, the northern and eastern zones with less consensus with respect to changes in the length of wet and dry spells. On the other hand drier conditions are projected for zone 5 via an increase in consecutive dry days and less intense rainfall events. It is important to note that though there is some consistency in the projections from the PRECIS model forced by the ECHAM4 and HadAM3P, there is still a need to analyze additional regional climate models driven by a suite of global climate models and to examine as well projections from statistical downscaling techniques.

The projections have implications for a number of sectors as they possibly suggest for some locations in the northern and eastern Caribbean greater chances of flash floods, greater run-off rates, and perhaps decreased water availability. This may lead to changes in growing cycles of some crops and changes in the spatial and temporal occurrences of vector borne diseases. Some of the future work will include 

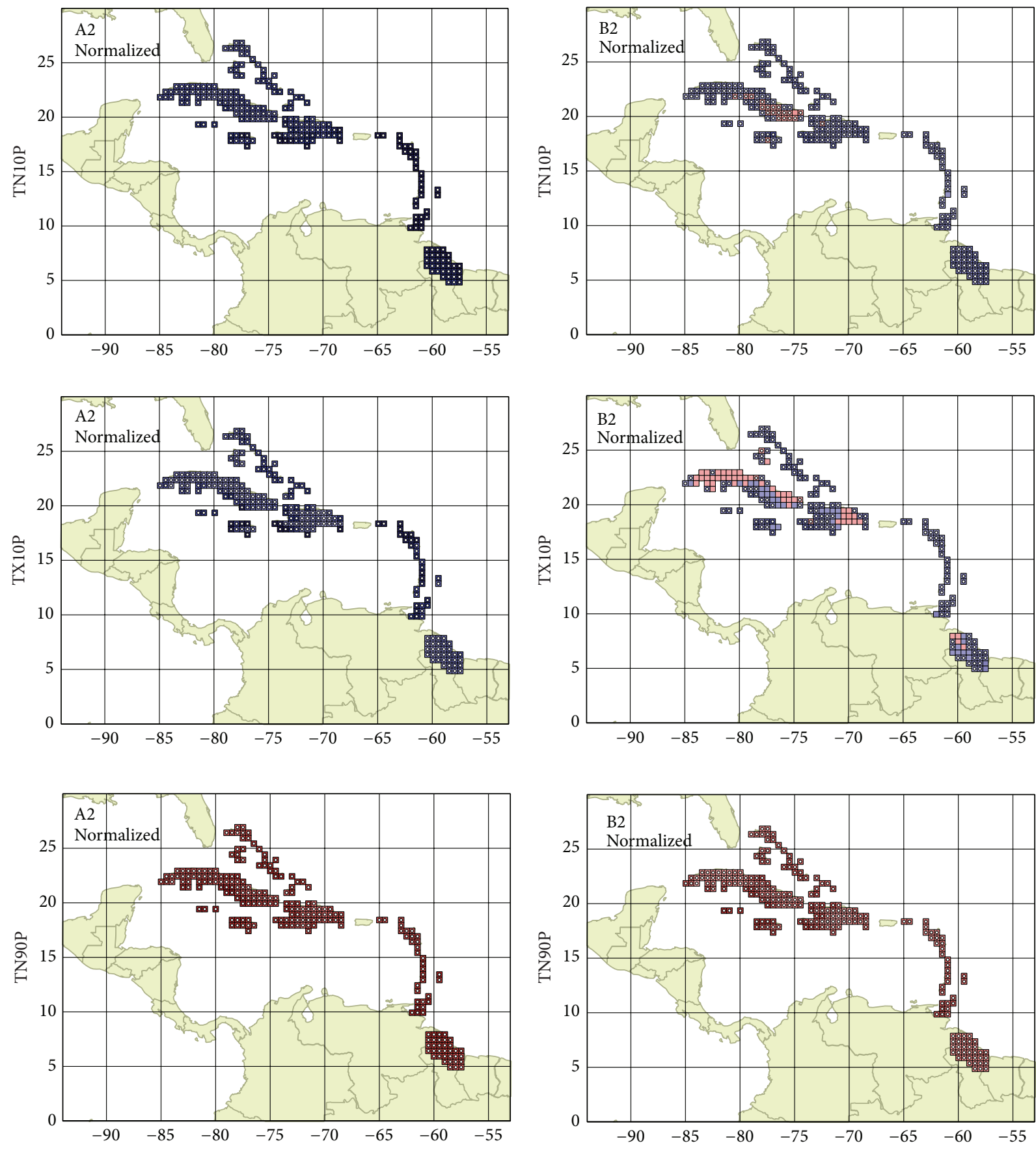
- -1.0 to -0.9
$\square \quad 0$ to 0.1
口 -0.9 to -0.8
0.1 to 0.2
口 -0.8 to -0.7
0.2 to 0.3
口 -0.7 to -0.6
0.3 to 0.4
$\square-0.6$ to -0.5
口 0.4 to 0.5
口 -0.5 to -0.4
口 0.5 to 0.6
$\square-0.4$ to -0.3
口 0.6 to 0.7
$\square-0.3$ to -0.2
口 0.7 to 0.8
$\square-0.2$ to -0.1
口 0.8 to 0.9
$\square-0.1$ to 0
- 0.9 to 1.0

$\begin{array}{ll}\square-1.0 \text { to }-0.9 & \square 0 \text { to } 0.1 \\ \square-0.9 \text { to }-0.8 & \square 0.1 \text { to } 0.2 \\ \square-0.8 \text { to }-0.7 & \square 0.2 \text { to } 0.3 \\ \square-0.7 \text { to }-0.6 & \square 0.3 \text { to } 0.4 \\ \square-0.6 \text { to }-0.5 & \square 0.4 \text { to } 0.5 \\ \square-0.5 \text { to }-0.4 & \square 0.5 \text { to } 0.6 \\ \square-0.4 \text { to }-0.3 & \square 0.6 \text { to } 0.7 \\ \square-0.3 \text { to }-0.2 & \square 0.7 \text { to } 0.8 \\ \square-0.2 \text { to }-0.1 & \square 0.8 \text { to } 0.9 \\ \square-0.1 \text { to } 0 & \square 0.9 \text { to } 1.0\end{array}$

FIgURE 7: Continued. 


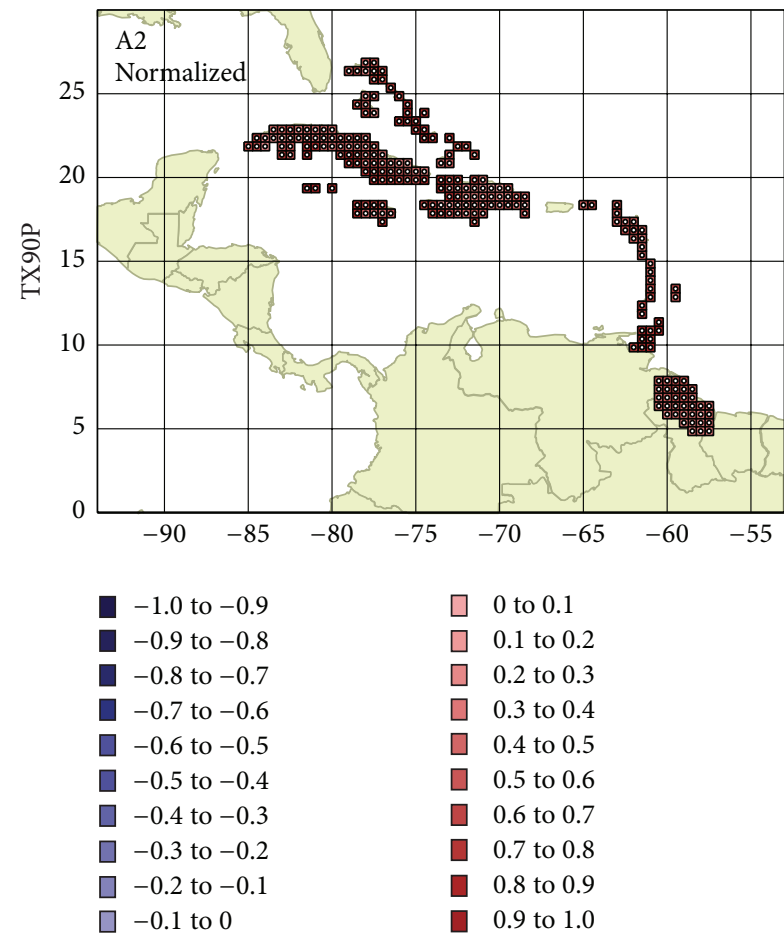

(a)

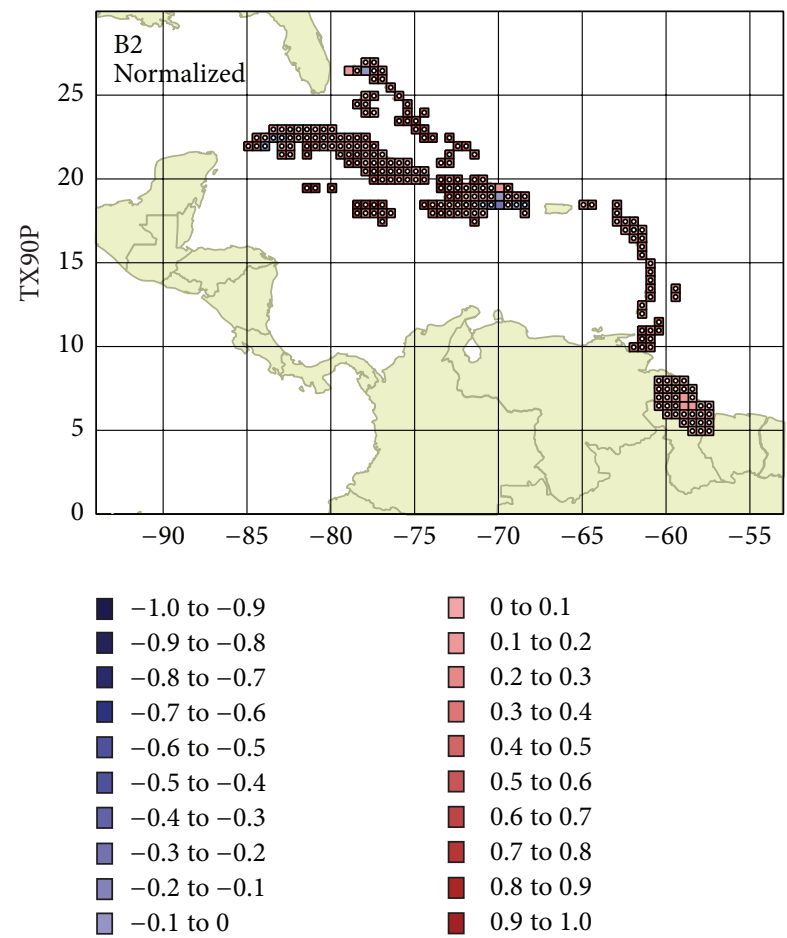

(a)

FIGURE 7: Projected normalized change in trends for TN10P, TX10P, TN90P and TX90P for 2071-2099 relative to 1961-1989 for the A2 (left panels) and B2 (right panels) IPCC SRES scenarios of each variable. Blue colour indicates negative and red colour indicates positive trends. Statistically significant trends are indicated with white stippling.

\begin{tabular}{|c|c|c|c|c|c|c|c|c|c|c|c|c|c|c|}
\hline \multicolumn{2}{|r|}{ Zones } & \multicolumn{2}{|c|}{1} & \multicolumn{2}{|c|}{2} & \multicolumn{2}{|c|}{3} & \multicolumn{2}{|c|}{4} & \multicolumn{2}{|c|}{5} & \multicolumn{2}{|c|}{ All } & \multirow[t]{2}{*}{ Units } \\
\hline & & A2 & B2 & A2 & B2 & A2 & B2 & A2 & B2 & A2 & B2 & A2 & B2 & \\
\hline \multirow{9}{*}{ 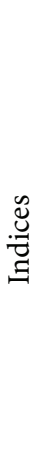 } & CDD & 0.0 & -0.3 & 0.0 & -0.2 & 0.0 & 0.0 & -0.1 & 0.0 & 0.3 & 0.2 & \begin{tabular}{|l|}
0.1 \\
\end{tabular} & -0.1 & days \\
\hline & CWD & 0.0 & \begin{tabular}{|l}
0.1 \\
0.1
\end{tabular} & 0.0 & 0.0 & 0.0 & 0.0 & 0.1 & 0.1 & 0.0 & -0.1 & 0.0 & 0.0 & days \\
\hline & R10 & -0.1 & 0.1 & 0.0 & 0.1 & 0.0 & 0.1 & 0.1 & -0.1 & -0.1 & 0.0 & 0.0 & 0.1 & days \\
\hline & R95P & -0.3 & 0.3 & 1.9 & 4.5 & 0.2 & 2.1 & 1.7 & -1.4 & -0.6 & -0.3 & 0.4 & 1.1 & $\mathrm{~mm}$ \\
\hline & RX5 & 0.7 & 0.1 & 1.1 & 2.2 & 0.3 & 0.8 & 0.0 & -0.8 & 0.1 & -0.2 & 0.5 & 0.5 & $\mathrm{~mm}$ \\
\hline & TN10P & -0.4 & -0.1 & -0.5 & 0.0 & -0.5 & -0.1 & -0.9 & 0.0 & -0.8 & -0.1 & -0.6 & -0.1 & $\%$ \\
\hline & TN90P & 0.6 & 0.4 & 0.7 & 0.4 & 0.5 & 0.3 & 0.6 & 0.3 & \begin{tabular}{|l|}
0.7 \\
\end{tabular} & 0.3 & \begin{tabular}{|l|}
0.6 \\
\end{tabular} & 0.4 & $\%$ \\
\hline & TX10P & -0.3 & 0.0 & -0.5 & -0.1 & -0.3 & 0.0 & -0.8 & -0.1 & -0.4 & 0.0 & $\mid-0.4$ & 0.0 & $\%$ \\
\hline & X90P & 0.6 & 0.3 & 0.6 & 0.4 & 0.4 & 0.2 & 0.6 & 0.3 & 0.6 & 0.6 & 0.5 & 0.3 & $\%$ \\
\hline
\end{tabular}

Figure 8: Change in linear trend for 2071-2099 relative to 1961-1989 for all indices across each zone and the entire Caribbean domain for the A2 and B2 scenarios. Trends are calculated using all grid points in the defined zones. Brown (green) cells indicate changes towards drier (wetter) conditions. Red (blue) indicates changes towards hotter (colder) conditions. CDD (CWD) is the maximum number of consecutive dry (wet) days; R10 is the annual count of days when precipitation is greater than or equal to $10 \mathrm{~mm}$; R95P is the annual total precipitation when rainfall is greater than the 95th percentile; RX5 is the annual highest 5-consecutive-day precipitation (mm); TX90 (TN90) is the percentage of days when maximum (minimum) temperature is greater than the 90th percentile; TX10 (TN10) is the percentage of days when maximum (minimum) temperature is less than the 10th percentile. 
translating projections from a $50 \mathrm{~km}$ grid to point locations and investigating possible sector specific impacts through modelling and integrated assessments. There is great need as well to investigate the drivers that facilitate the changes projected and to examine changes in extremes by seasons to understand why yearly patterns manifest.

The importance of meteorological data and sector data must be underscored as these are essential to characterizing present climate trends, investigating rare and moderate extreme events, validating models, and understanding the relationship between climate and various natural systems. Progress continues to be made through regional and international partnerships which facilitate data monitoring and rescue, analysis of extremes, downscaling initiatives, integrated assessments, and adaptation efforts of small island states.

\section{Conflict of Interests}

The authors declare that there is no conflict of interests regarding the publication of this paper.

\section{Acknowledgments}

Thanks are due to John Charlery of the University of the West Indies in Barbados for the useful comments received during the writeshop held in Barbados in 2012 funded by the Caribbean Community Climate Change Centre. Thanks are also due to the anonymous reviewer whose suggestions have assisted in drafting an improved paper.

\section{References}

[1] M. A. Taylor, A. Centella, J. Charlery et al., "The precis Caribbean story lessons and legacies," Bulletin of the American Meteorological Society, vol. 94, no. 7, pp. 1065-1073, 2013.

[2] J. T. Houghton and B. A. Callander, Climate Change 1992: The Supplementary Report to the IPCC Scientific Assessment: [Combined with Supporting Scientific Material], Cambridge University Press, Cambridge, UK, 1990.

[3] M. A. Taylor, F. S. Whyte, T. S. Stephenson, and J. D. Campbell, "Why dry? Investigating the future evolution of the Caribbean low level Jet to explain projected Caribbean drying," International Journal of Climatology, vol. 33, no. 3, pp. 784-792, 2013.

[4] A. V. Karmalkar, M. A. Taylor, J. Campbell et al., "A review of observed and projected changes in climate for the islands in the Caribbean," Atmosfera, vol. 26, no. 2, pp. 283-309, 2013.

[5] J. D. Campbell, M. A. Taylor, T. S. Stephenson, R. A. Watson, and F. S. Whyte, "Future climate of the Caribbean from a regional climate model," International Journal of Climatology, vol. 31, no. 12, pp. 1866-1878, 2011.

[6] J. L. Bamber, R. E. M. Riva, B. L. A. Vermeersen, and A. M. Lebrocq, "Reassessment of the potential sea-level rise from a collapse of the west antarctic ice sheet," Science, vol. 324, no. 5929, pp. 901-903, 2009.

[7] A. Hu, G. A. Meehl, W. Han, and J. Yin, "Transient response of the MOC and climate to potential melting of the Greenland Ice Sheet in the 21st century," Geophysical Research Letters, vol. 36, no. 10, 2009.

[8] C. McSweeney, M. New, and G. Lizcano, UNDP Climate Change Country Profiles, School of Geography and the Environment,
University of Oxford, Oxford, UK, 2008, http://www.geog.ox.ac .uk/research/climate/projects/undp-cp/.

[9] J. H. Christensen, B. Hewitson, A. Busuioc et al., "Regional climate projections," in Climate Change 2007: The Physical Science Basis. Contribution of Working Group I to the Fourth Assessment Report of the Intergovernmental Panel on Climate Change, S. Solomon, D. Qin, M. Manning et al., Eds., pp. 847940, Cambridge University Press, Cambridge, United Kingdom and, Cambridge, Mass, USA, 2007.

[10] M. E. Angeles, J. E. Gonzalez, D. J. Erickson III, and J. L. Hernández, "Predictions of future climate change in the caribbean region using global general circulation models," International Journal of Climatology, vol. 27, no. 5, pp. 555-569, 2007.

[11] A. A. Chen, C. L. Rhoden, and M. A. Taylor, "Climate change science and future climate change scenarios," in Climate Change Impact on Dengue: The Caribbean Experience, Climate Studies Mona, A. A. Chen, D. D. Chadee, and S. C. Rawlins, Eds., pp. 66-77, University of the West Indies, International START Secretariat, Washington, DC, USA, 2006.

[12] B. Singh, "Climate-related global changes in the southern Caribbean: Trinidad and Tobago," Global and Planetary Change, vol. 15, no. 3-4, pp. 93-111, 1997.

[13] B. Singh, "Climate changes in the Greater and Southern Caribbean," International Journal of Climatology, vol. 17, no. 10, pp. 1093-1114, 1997.

[14] T. C. Hall, A. M. Sealy, T. S. Stephenson et al., "Future climate of the Caribbean from a super-high-resolution atmospheric general circulation model," Theoretical and Applied Climatology, vol. 113, no. 1-2, pp. 271-287, 2013.

[15] C. McSweeney, M. New, G. Lizcano, and X. Lu, “The UNDP climate change country profiles improving the accessibility of observed and projected climate information for studies of climate change in developing countries," Bulletin of the American Meteorological Society, vol. 91, no. 2, pp. 157-166, 2010.

[16] T. Nakaegawa, A. Kitoh, Y. Ishizaki, S. Kusunoki, and H. Murakami, "Caribbean low-level jets and accompanying moisture fluxes in a global warming climate projected with CMIP3 multi-model ensemble and fine-mesh atmospheric general circulation models," International Journal of Climatology, vol. 34, no. 4, pp. 964-977, 2014.

[17] IPCC, Managing the Risks of Extreme Events and Disasters to Advance Climate Change Adaptation. A Special Report of Working Groups I and II of the Intergovernmental Panel on Climate Change, edited by C. B. Field, V. Barros, T. F. Stocker etal, Cambridge University Press, Cambridge, UK, 2012, http://ipcc-wg2 .gov/SREX/report/full-report/.

[18] Climate and Development Knowledge Network 201 Climate and Development Knowledge Network (CDKN), Managing Climate Extremes and Disasters in Latin America and the Caribbean: Lessons from the SREX Report, Overseas Development Institute, 2012, This report was compiled by Catherine Cameron, Gemma Norrington-Davies and Dr. Victoria te Velde of Agulhas: Applied Knowledge, with the guidance of Dr. Tom Mitchell, http://cdkn.org/srex/, http://cdkn.org/wp-content/ uploads/2012/04/CDKN001_CDKN-RFQ_LAC-report_electronic.pdf.

[19] R. S. Pulwarty, L. A. Nurse, and U. O. Trotz, "Caribbean Islands in a Changing Climate Environment," 2010, http://www.environmentmagazine.org/Archives/Back\%20Issues/November-December\%202010/caribbean-islands-full.html.

[20] M. C. Simpson, D. Scott, M. Harrison et al., Quantification and Magnitude of Losses and Damages Resulting from the Impacts 
of Climate Change: Modelling the Transformational Impacts and Costs of Sea Level Rise in the Caribbean, Summary Document, United Nations Development Programme (UNDP), Barbados, North America, 2010.

[21] J. A. Marengo, R. Jones, L. M. Alves, and M. C. Valverde, "Future change of temperature and precipitation extremes in south america as derived from the precis regional climate modeling system," International Journal of Climatology, vol. 29, no. 15, pp. 2241-2255, 2009.

[22] T. S. Stephenson, C. M. Goodess, M. R. Haylock, A. A. Chen, and M. A. Taylor, "Detecting inhomogeneities in Caribbean and adjacent Caribbean temperature data using sea-surface temperatures," Journal of Geophysical Research D: Atmospheres, vol. 113, no. 21, Article ID D21116, 2008.

[23] M. Jury, B. A. Malmgren, and A. Winter, "Subregional precipitation climate of the Caribbean and relationships with ENSO and NAO," Journal of Geophysical Research D: Atmospheres, vol. 112, no. 16, Article ID D16107, 2007.

[24] J. M. Spence, M. A. Taylor, and A. A. Chen, "The effect of concurrent sea-surface temperature anomalies in the tropical Pacific and Atlantic on Carribean rainfall," International Journal of Climatology, vol. 24, no. 12, pp. 1531-1541, 2004.

[25] A. A. Chen and M. A. Taylor, "Investigating the link between early season Caribbean rainfall and the El Niño+1 year," International Journal of Climatology, vol. 22, no. 1, pp. 87-106, 2002.

[26] A. Giannini, Y. Kushnir, and M. A. Cane, "Interannual variability of Caribbean rainfall, ENSO, and the Atlantic Ocean," Journal of Climate, vol. 13, no. 2, pp. 297-311, 2000.

[27] M. R. Jury, "An intercomparison of observational, reanalysis, satellite, and coupled model data on mean rainfall in the Caribbean," Journal of Hydrometeorology, vol. 10, no. 2, pp. 413430, 2009.

[28] T. S. Stephenson, L. A. Vincent, T. Allen et al., "Changes in extreme temperature and precipitation in the Caribbean region, 1961-2010," International Journal of Climatology, vol. 34, no. 9, pp. 2957-2971, 2014.

[29] T. C. Peterson, M. A. Taylor, R. Demeritte et al., "Recent changes in climate extremes in the caribbean region," Journal of Geophysical Research: Atmospheres, vol. 107, no. D21, pp. ACL 16-1-ACL 16-9, 1984.

[30] P. Y. Groisman, T. R. Karl, D. R. Easterling et al., "Changes in the probability of heavy precipitation: important indicators of climatic change," Climatic Change, vol. 42, no. 1, pp. 243-283, 1999.

[31] P. Frich, L. V. Alexander, P. Della-Marta et al., "Observed coherent changes in climatic extremes during the second half of the twentieth century," Climate Research, vol. 19, no. 3, pp. 193-212, 2002.

[32] L. A. Vincent, E. Aguilar, M. Saindou et al., "Observed trends in indices of daily and extreme temperature and precipitation for the countries of the western Indian Ocean, 1961-2008," Journal of Geophysical Research D: Atmospheres, vol. 116, no. 10, Article ID D10108, 2011.

[33] E. Aguilar, T. C. Peterson, P. R. Obando et al., "Changes in precipitation and temperature extremes in Central America and northern South America, 1961-2003," Journal of Geophysical Research D: Atmospheres, vol. 110, no. 23, pp. 1-15, 2005.

[34] L. A. Vincent, T. C. Peterson, V. R. Barros et al., "Observed trends in indices of daily temperature extremes in South America 1960-2000," Journal of Climate, vol. 18, no. 23, pp. 50115023, 2005.
[35] M. R. Haylock, T. C. Peterson, L. M. Alves et al., "Trends in total and extreme South American rainfall in 1960-2000 and links with sea surface temperature," Journal of Climate, vol. 19, no. 8, pp. 1490-1512, 2006.

[36] M. D. L. M. Skansi, M. Brunet, J. Sigró et al., "Warming and wetting signals emerging from analysis of changes in climate extreme indices over South America," Global and Planetary Change, vol. 100, pp. 295-307, 2013.

[37] M. New, B. Hewitson, D. B. Stephenson et al., "Evidence of trends in daily climate extremes over southern and west Africa," Journal of Geophysical Research D: Atmospheres, vol. 111, no. 14, 2006.

[38] E. Aguilar, A. A. Barry, M. Brunet et al., "Changes in temperature and precipitation extremes in western central Africa, Guinea Conakry, and Zimbabwe, 1955-2006," Journal of Geophysical Research D: Atmospheres, vol. 114, no. 2, Article ID D02115, 2009.

[39] X. Zhang, E. Aguilar, S. Sensoy et al., "Trends in Middle East climate extreme indices from 1950 to 2003," Journal of Geophysical Research D: Atmospheres, vol. 110, no. 22, Article ID D22104, 2005.

[40] A. M. G. Klein Tank, T. C. Peterson, D. A. Quadir et al., "Changes in daily temperature and precipitation extremes in central and south Asia," Journal of Geophysical Research D: Atmospheres, vol. 111, no. 16, Article ID D16105, 2006.

[41] G. M. Griffiths, L. E. Chambers, M. R. Haylock et al., "Change in mean temperature as a predictor of extreme temperature change in the Asia-Pacific region," International Journal of Climatology, vol. 25, no. 10, pp. 1301-1330, 2005.

[42] J. Caesar, L. V. Alexander, B. Trewin et al., "Changes in temperature and precipitation extremes over the Indo-Pacific region from 1971 to 2005," International Journal of Climatology, vol. 31, no. 6, pp. 791-801, 2011.

[43] M. G. Donat, T. C. Peterson, M. Brunet et al., "Changes in extreme temperature and precipitation in the Arab region: long-term trends and variability related to ENSO and NAO," International Journal of Climatology, vol. 34, no. 3, pp. 581-592, 2014.

[44] L. V. Alexander, X. Zhang, T. C. Peterson et al., "Global observed changes in daily climate extremes of temperature and precipitation," Journal of Geophysical Research D: Atmospheres, vol. 111, no. 5, Article ID D05109, 2006.

[45] M. G. Donat, L. V. Alexander, H. Yang et al., "Updated analyses of temperature and precipitation extreme indices since the beginning of the twentieth century: the HadEX2 dataset," Journal of Geophysical Research D: Atmospheres, vol. 118, no. 5, pp. 2098-2118, 2013.

[46] A. M. G. Klein Tank, F. W. Zwiers, and X. Zhang, "Guidelines on analysis of extremes in a changing climate in support of informed decisions for adaptation," WCDMP-No.72, WMO-TD No.1500, 52pp.

[47] J. D. Neelin, M. Münnich, H. Su, J. E. Meyerson, and C. E. Holloway, "Tropical drying trends in global warming models and observations," Proceedings of the National Academy of Sciences of the United States of America, vol.103, no. 16, pp. 61106115, 2006.

[48] L. A. Nurse and G. Sem, "Small island States," in Climate Change 2001-The Scientific Basis, Contribution of Working Group 1 to the Third Assessment Report of the Intergovernmental Panel on Climate Change (IPCC), J. T. Houghton, Y. Ding, D. J. Griggs, M. Noguer, P. J. van der Linden, and D. Xiaosu, Eds., pp. 843875, Cambridge University Press, Cambridge, UK, 2001. 
[49] M. A. Taylor, D. B. Enfield, and A. A. Chen, "Influence of the tropical Atlantic versus the tropical Pacific on Caribbean rainfall," Journal of Geophysical Research C: Oceans, vol. 107, no. 9, pp. 10-1, 2002.

[50] R. Aparicio, "Meteorological and oceanographic conditions along the southern coastal boundary of the Caribbean Sea, 19511986," in Climate Change in the Intra-Americas Sea, G. A. Maul, Ed., pp. 100-114, United Nations Environment Program, IOC, Arnold, London, UK, 1993.

[51] R. P. D. Walsh, "Climatic changes in the eastern caribbean over the past 150 years and some implications in planning sustainable development," in Resource Sustainability and Caribbean Development, D. F. M. McGregor, D. Barker, and S. L. Evans, Eds., pp. 51-68, Kingston: The Press University of the West Indies, 1998.

[52] H. C. Martin and P. S. Weech, "Change in the Bahamas? evidence in the meteorological record," Bahamas Journal of Science, vol. 8, no. 2, pp. 22-32, 2001.

[53] D. W. Gamble and S. Curtis, "Caribbean precipitation: review, model and prospect," Progress in Physical Geography, vol. 32, no. 3, pp. 265-276, 2008.

[54] A. Chen, M. Taylor, A. Centella, and D. Farrell, "Climate trends and scenarios for climate change in the insular Caribbean: report of working group I, climate change and biodiversity in the insular Caribbean," CANARI Technical Report 381, Caribbean Natural Resources Institute, Trinidad, Calif, USA, 2008.

[55] R. G. Jones, D. Hassell, D. Hudson, S. Wilson, G. Jenkins, and J. Mitchell, Workbook on Generating High Resolution Climate Change Scenarios Using PRECIS, UNDP, New York, NY, USA, 2003.

[56] R. G. Jones, M. Noger, D. C. Hassell et al., Generating High Resolution Climate Change Scenarios using PRECIS, Met Office Hadley Centre, Exeter, UK, 2004.

[57] A. Moberg and P. D. Jones, "Regional climate model simulations of daily maximum and minimum near-surface temperatures across Europe compared with observed station data 1961-1990," Climate Dynamics, vol. 23, no. 7-8, pp. 695-715, 2004.

[58] M. Tadross, C. Jack, and B. Hewitson, "On RCM-based projections of change in southern African summer climate," Geophysical Research Letters, vol. 32, no. 23, pp. 1-4, 2005.

[59] K. Rupa Kumar, A. K. Sahai, K. Krishna Kumar et al., "Highresolution climate change scenarios for India for the 21st century," Current Science, vol. 90, no. 3, pp. 334-345, 2006.

[60] Y. Zhang, Y. Xu, W. Dong, L. Cao, and M. Sparrow, "A future climate scenario of regional changes in extreme climate events over China using the PRECIS climate model," Geophysical Research Letters, vol. 33, no. 24, 2006.

[61] A. Bloom, V. Kotroni, and K. Lagouvardos, "Climate change impact of wind energy availability in the Eastern Mediterranean using the regional climate model PRECIS," Natural Hazards and Earth System Sciences, vol. 8, no. 6, pp. 1249-1257, 2008.

[62] V. Kotroni, S. Lykoudis, K. Lagouvardos, and D. Lalas, "A fine resolution regional climate change experiment for the Eastern Mediterranean: analysis of the present climate simulations," Global and Planetary Change, vol. 64, no. 1-2, pp. 93-104, 2008.

[63] S. U. Islam, N. Rehman, and M. M. Sheikh, "Future change in the frequency of warm and cold spells over Pakistan simulated by the PRECIS regional climate model," Climatic Change, vol. 94, no. 1-2, pp. 35-45, 2009.

[64] A. Centella, A. Bezanilla, and K. Leslie, "A study of the uncertainty in future Caribbean climate using the PRECIS regional climate model," Tech. Rep., Community Caribbean Climate Change Center, Belmopan, Belize, 2008.
[65] W. Ebisuzaki, "A method to estimate the statistical significance of a correlation when the data are serially correlated," Journal of Climate, vol. 10, no. 9, pp. 2147-2153, 1997.

[66] R. G. Curry, M. S. McCartney, and T. M. Joyce, "Oceanic transport of subpolar climate signals to mid-depth subtropical waters," Nature, vol. 391, no. 6667, pp. 575-577, 1998. 

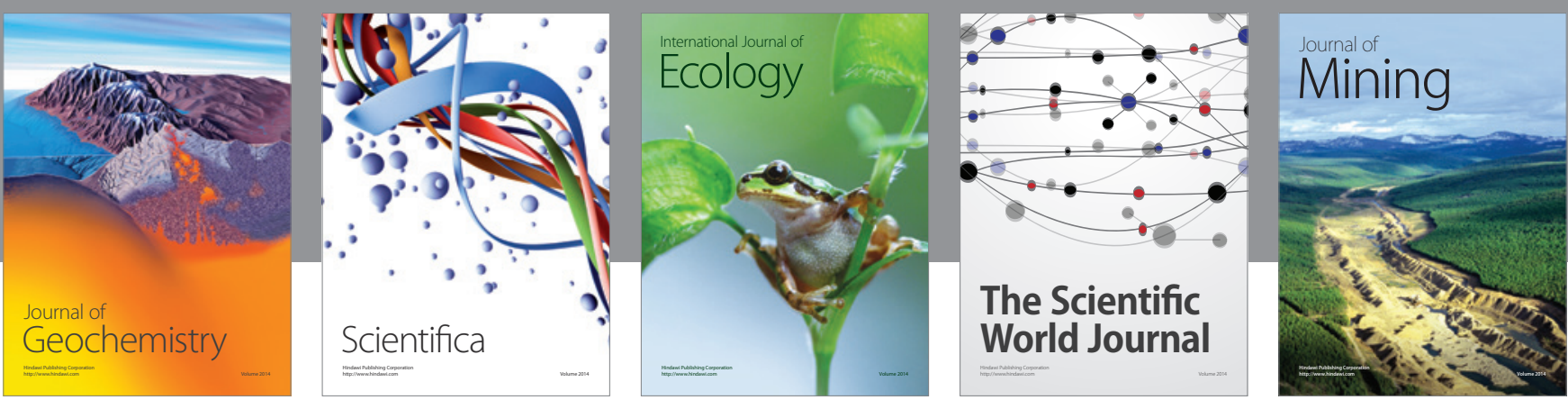

The Scientific World Journal
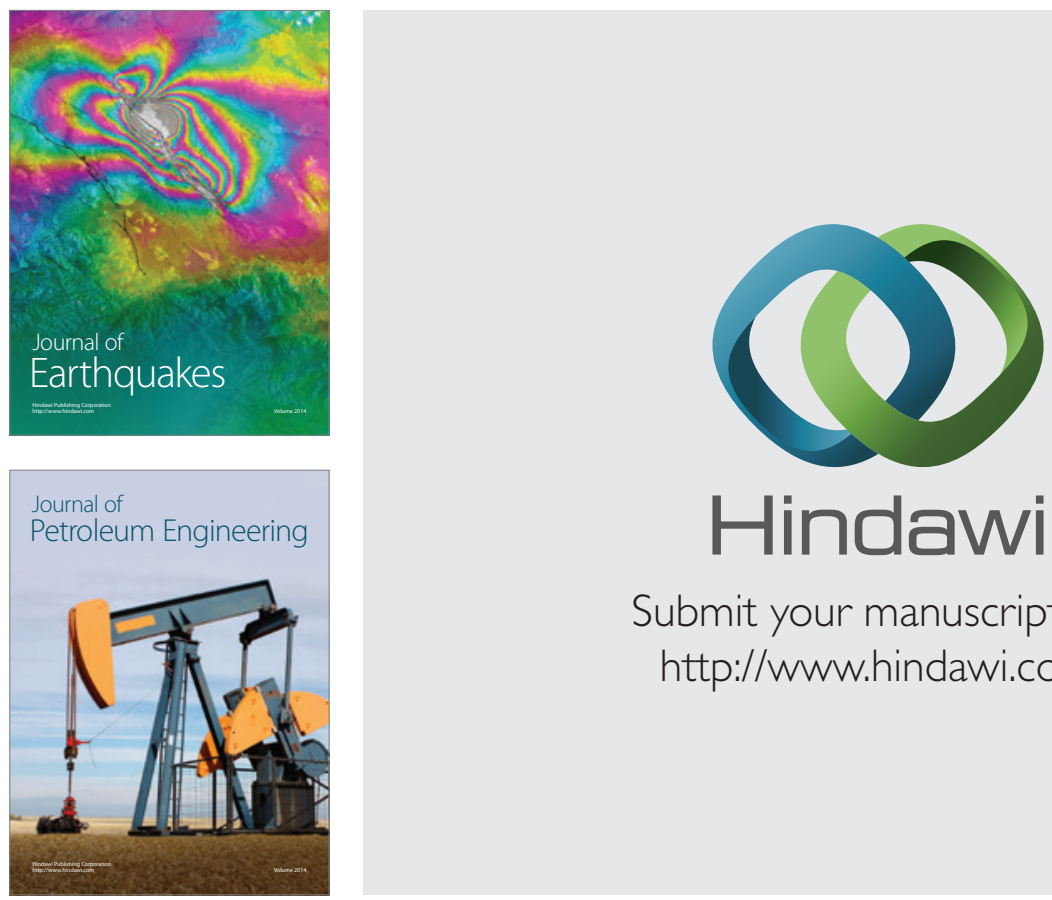

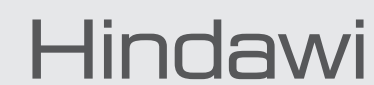

Submit your manuscripts at

http://www.hindawi.com
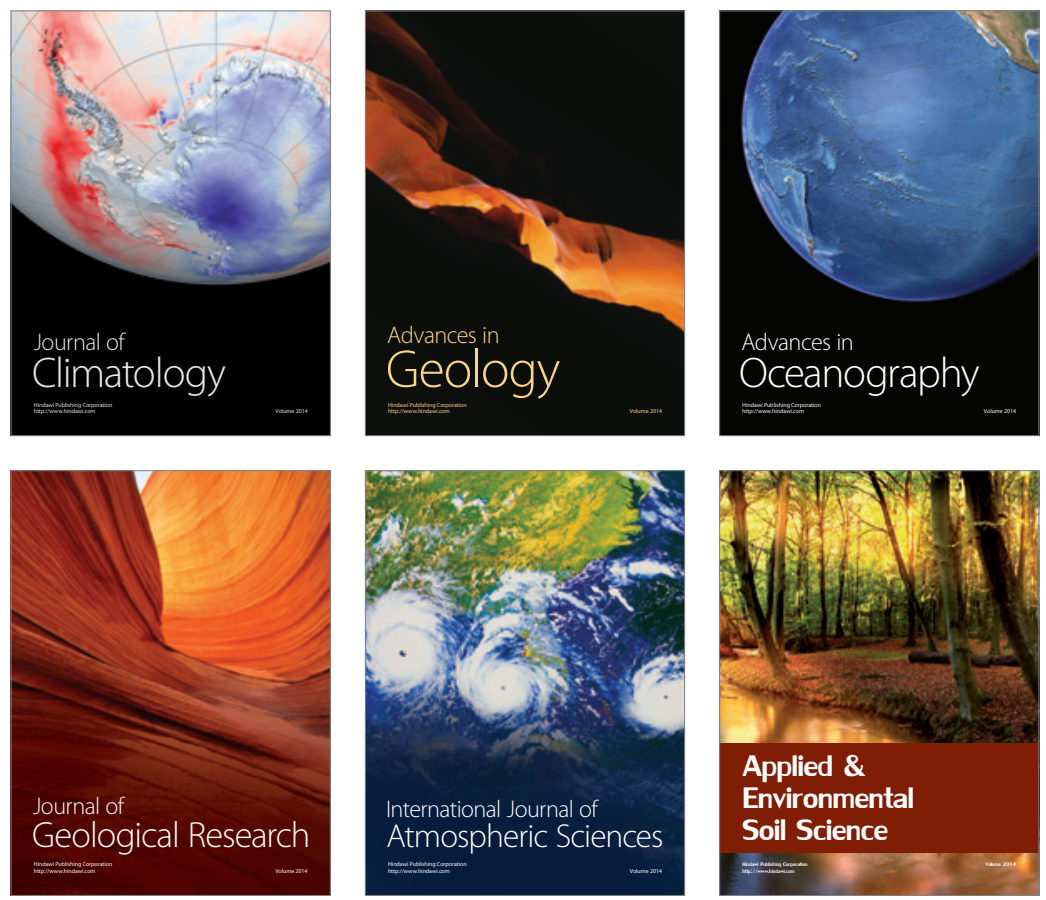
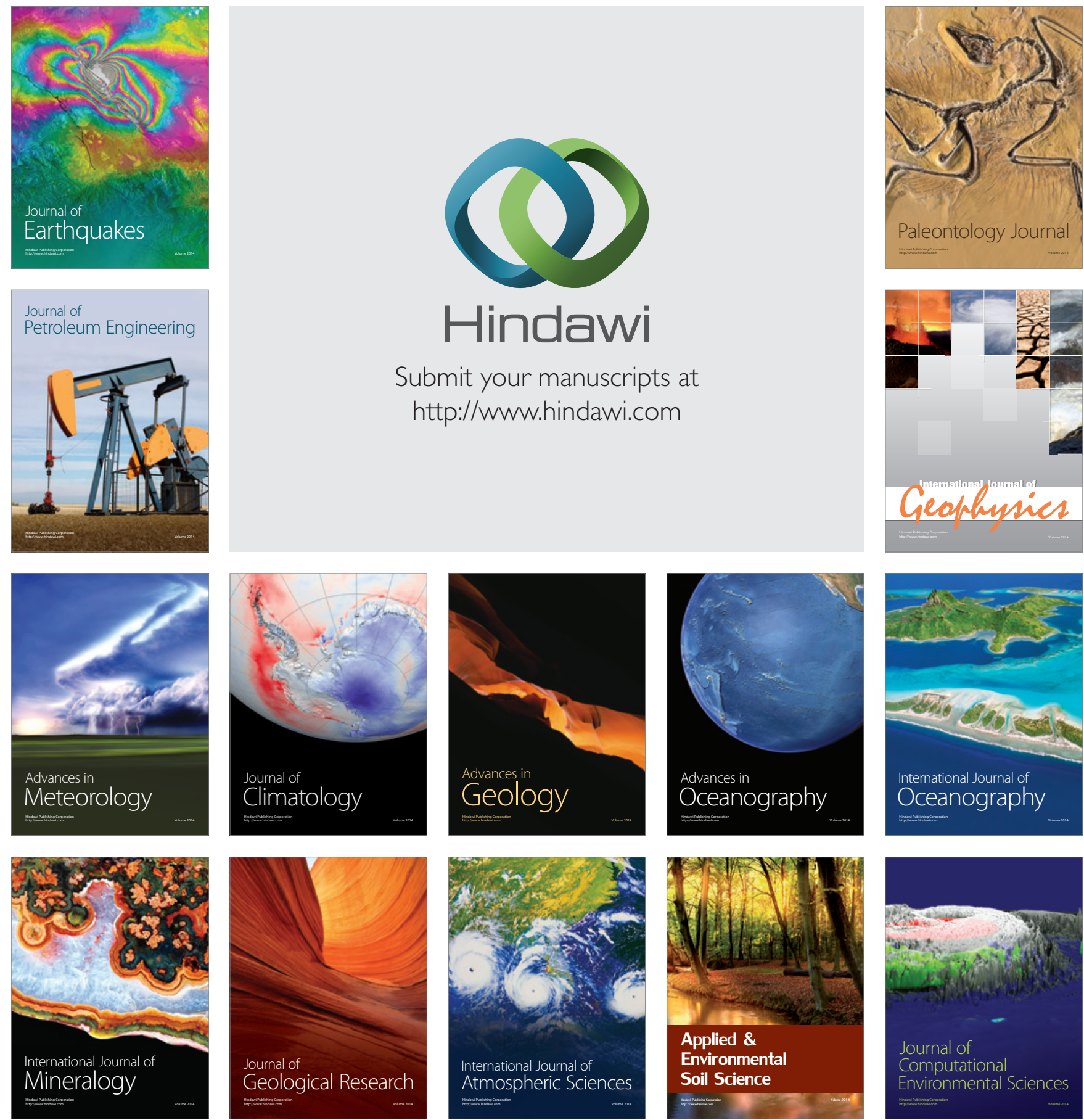